\title{
Research on micro milling mechanism and surface roughness of high volume fraction SiCp/Al composites
}

Po Jin

Liaoning University of Technology

Qi Gao ( $\nabla$ qqonline@163.com )

Liaoning University of Technology

Quanzhao Wang

Chinese Academy of Science

Wenbo Li

Liaoning University of Technology

\section{Research Article}

Keywords: SiCp/Al composite, Micro-milling, Milling mechanism, Surface roughness, Orthogonal experiment

Posted Date: February 4th, 2021

DOI: https://doi.org/10.21203/rs.3.rs-167276/v1

License: (9) This work is licensed under a Creative Commons Attribution 4.0 International License. Read Full License 


\title{
Research on micro milling mechanism and surface roughness of high volume fraction $\mathrm{SiCp} / \mathrm{Al}$ composites
}

\author{
Po Jin', Qi Gao', Quanzhao Wang ${ }^{2}$, and Wenbo $\mathbf{L i}^{1}$ \\ ${ }^{1}$ School of Mechanical Engineering and Automation,Liaoning University of Technology, 121001 \\ ${ }^{2}$ Institute of Metal Research, Chinese Academy of Science, 110016 \\ This work is supported by: 1. the National Natural Science Foundation of China (No.51775100); 2. the Doctoral Start-up Fund of Liaoning \\ Province (2019-BS-123). \\ Corresponding author: Qi Gao ( qqonline@163.com).
}

\begin{abstract}
In this paper, the finite element simulation model of diamond tool milling $\mathrm{SiCp} / \mathrm{Al}$ composites was established.The milling force, stress distribution and removal mechanism of $\mathrm{SiC}$ reinforced granular material were studied. The correctness of finite element simulation is verified by micro milling experiments. The results show that the maximum stress mainly occurs when the SiC particles are milled with PCD tool. The removal mechanism of particles is different when the tool is milling particles at different positions. The material surface defects are reduced and the surface quality is improved as the cutting speed is increased. The surface defects of $\mathrm{SiCp} / \mathrm{Al}$ milling with single edge diamond milling tool mainly include cavities, microcracks, scratches and pits. According to the measurement results, it can be founded that the milling depth has the greatest influence on the surface roughness, followed by the spindle speed and the feed speed.
\end{abstract}

Keyword: SiCp/Al composite, Micro-milling, Milling mechanism, Surface roughness, Orthogonal experiment

\section{Introduction}

With the increasing demand for material properties in the fields of aerospace, automotive and optical precision instruments. Silicon carbide particle aluminum matrix composites ( $\mathrm{SiCp} / \mathrm{Al})$ have attracted more and more attention due to their excellent properties [1]. The $\mathrm{SiCp} / \mathrm{Al}$ composites have excellent comprehensive properties such as high specific strength and modulus, high temperature resistance, etc. The $\mathrm{SiCp} / \mathrm{Al}$ components are mainly used in satellite bearings, aircraft engines and inertial navigation systems [2]. As the urgent need of $\mathrm{SiCp} / \mathrm{Al}$ composites in various projects, the processing technology of $\mathrm{SiCp} / \mathrm{Al}$ composites has been widely concerned by scholars [3].

Song Min et al [4-5] founded that with the increase of $\mathrm{SiC}$ particle volume fraction, the yield strength and tensile strength increased, while the elongation decreased. Subsequently, Tao Wang et al. [6] established a twodimensional finite element simulation model to study the milling process of $\mathrm{SiCp} / \mathrm{Al}$ matrix composite materials. He founded that the main causes of surface defects were extrusion, pull-out and crushing of particles. Xiangyu Teng et al. [7] established a two-dimensional finite element simulation model considering the cutting edge radius, and analyzed the interaction between the cutter and particles and the process of chip formation. The distribution of cutting stress and strain in the workpiece under the influence of different cutting depth is studied. Zhichao Niu et al. [8] conducted a processing experiment with polycrystalline diamond (PCD) tool on a high-precision miniature milling machine. The surface roughness, morphology, texture and defect of workpiece were analyzed. And the optimum technological parameters are selected. Alokesh Pramanik et al. [9] performed milling on nanoparticle reinforced aluminum matrix composites. The results show that the surface roughness of the workpiece increases with the increase of feeding speed. The surface roughness of the workpiece decreases with the increase of feed per tooth, at a higher feed rate $(100-140 \mathrm{~m} / \mathrm{min})$. Junwei Liu et al. [10] established a force prediction model for $\mathrm{SiCp} / \mathrm{Al}$ composites. He founded that the maximum milling force increases with the increase of feed per tooth and milling depth. U. A. Dabade et al. [11] studied two kinds of $\mathrm{SiC}$ composites with volume fraction of $10 \%$. The effects of feed rate and cutting depth on cutting force, surface roughness and preheating temperature are revealed. Ying Fei Ge et al. [12] studied the wear condition, chip formation and surface generation of the cutter when the low-body $\mathrm{SiCp} / 2009 \mathrm{Al}$ composite material was processed at ultra-high speed. Junwei Liu et Al. [13] conducted an experimental study on micro-milling of $45 \% \mathrm{SiCp} / \mathrm{Al}$ composites. And founded that the surface roughness decreases first and then increases with the increase of feed. Beibei Wang et al. [14] simulated the high speed milling process of $\mathrm{SiCp} / \mathrm{Al} 6063$ composites with high volume fraction. The interaction among matrix, particle and tool during cutting was studied. The cutting mechanism of the material is also revealed.Tao Wang et al. [15] studied the milling process of $\mathrm{SiCp} / \mathrm{Al}$ composites with high volume fraction and small particle size. The effects of milling speed, feed rate and particle size on tool wear are revealed. YanmingQuan et al. [16] studied the hardness and residual stress of $\mathrm{SiCp} / \mathrm{Al}$ composites during processing. The results show that the residual stress on the surface of coarsegrained reinforced composites may be released due to structural defects. However, the residual stress on the surface of the composite reinforced by fine grains tends to compress. R. Bian et al. [17] conducted precision milling research on $\mathrm{SiCp} / \mathrm{Al}$ composites with high volume fraction 
and large granularity. The cutting mechanism and wear characteristics of $\mathrm{SiCp} / \mathrm{Al}$ composites are revealed. M. Bhuvanesh Kumar et al. [18] fabricated $\mathrm{SiC}$ and $\mathrm{B} 4 \mathrm{C}$ reinforced aluminum composites with three different components using agitation casting technique. Experiments were carried out on these materials with different machining parameters, and the most influential milling parameters were found. XiangyuTeng et al. [19] investigated the cutting mechanism of two $\mathrm{SiCp} / \mathrm{Al}$ composites with different particle sizes. It was found that the nanoscale particles remained intact during the cutting process without breaking, which may produce continuous chip. However, micron-sized particles are prone to fracture and tend to produce discontinuous chips. Compared with micron size, nanometer size materials can achieve better surface quality and fewer defects.

Due to the strengthening effect of silicon carbide particles in the material, $\mathrm{SiCp} / \mathrm{Al}$ composites have excellent properties. At the same time, the surface quality of the processed material is difficult to control, which is a typical refractory material [20]. Micro milling is an important machining method in the field of mechanical processing, which has many advantages, such as high machining accuracy, low machining cost and so on. Therefore, the micro milling technology is applied to the processing of composite materials to realize the flexible and precision processing of composite parts [21-22].

The removal characteristics of composites are different from those of conventional machining. Both the size effect of plastic material and the removal of brittle material affect the surface formation of composite materials. In this paper, finite element simulation and micro milling experiments are combined to study the material milling mechanism and surface defect formation mechanism of $\mathrm{SiCp} / \mathrm{Al}$ composites in micro cutting. The influence of spindle speed, feed speed and milling depth on surface quality is analyzed. Furthermore, the optimization of the combination of process parameters is carried out to further improve the surface quality of the material and promote its industrial application.

\section{Simulation analysis based on particle random distribution model}

$\mathrm{SiCp} / \mathrm{Al}$ matrix composite is a two-phase heterogeneous material composed of aluminum alloy matrix and micron grade silicon carbide particles. Because the characteristics of two-phase materials are different, the model of particle random distribution is constructed and the simulation experiment is carried out.

2.1Establishment of random particle distribution model

The finite element model of $\mathrm{SiCp} / \mathrm{Al}$ composites with different particle size distribution was established. In order to observe the particle removal mechanism in the cutting process more clearly, and avoid non-convergence in the simulation process. The 3D micro-milling model is simplified to a 2D orthogonal simulation experiment. Schematic diagram of milling model is shown in Fig.1. The particle volume fraction of composites is $60 \%$. The particle diameter is mainly composed of $20 \mathrm{~m}$ and $60 \mathrm{~m}$ particles. The average particle size is $40 \mathrm{~m}$, and the matrix material is Al2024. It is assumed that the particle shape is circular and the particles are randomly distributed in the matrix without overlapping. The random distribution of particles is obtained, as shown in Fig.2.

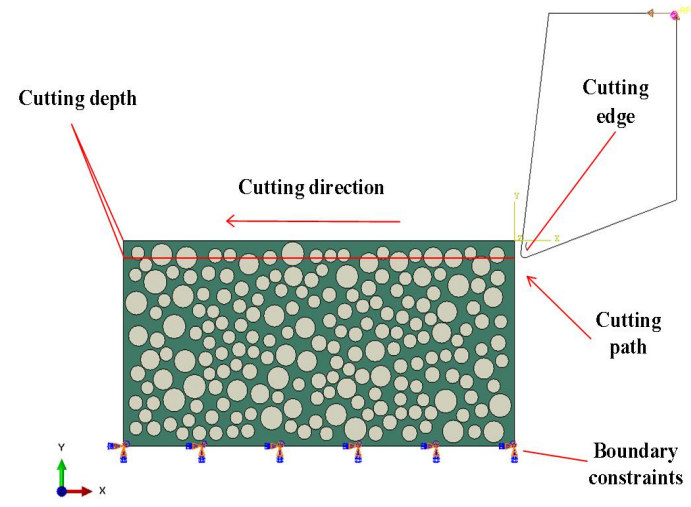

Figure 1. Schematic diagram of a milling model

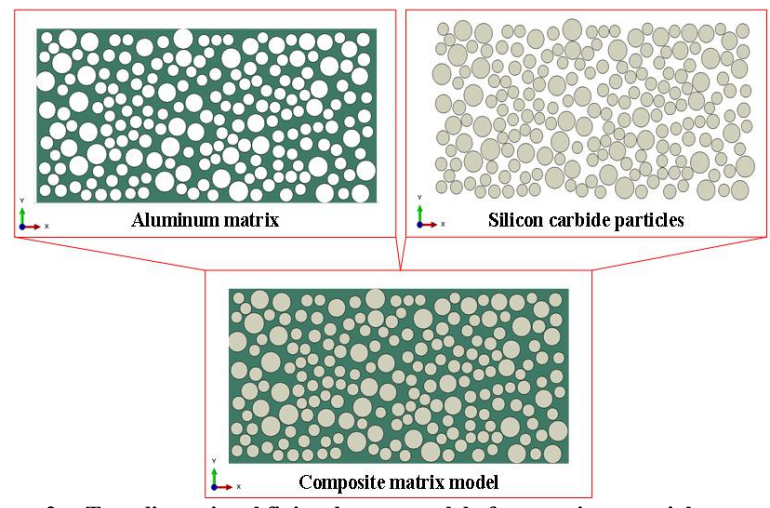

Figure 2. Two-dimensional finite element model of composite materials

\subsection{Material characteristics and failure criteria}

The matrix of the composite is Al2024 and the reinforcement is $\mathrm{SiC}$ particles. The elastic phase of the material is mainly determined by elastic modulus and Poisson's ratio. Some parameters are shown in Table 1. The deformation mode and chip formation form of aluminum matrix and silicon carbide particles were set respectively.

\begin{tabular}{ccc}
\multicolumn{3}{c}{ Table 1 Material parameters of A12024 and SiC } \\
\hline \hline Material & Matrix: A12024 & Particles: $\mathrm{SiC}$ \\
\hline Density $\left(\mathrm{g} / \mathrm{cm}^{3}\right)$ & 2.77 & 3.13 \\
Elastic modulus $(\mathrm{GPa})$ & 73 & 427.5 \\
Poisson's ratio & 0.33 & 0.14 \\
Thermal conductivity $(\mathrm{W} /(\mathrm{mk}))$ & 190 & 81 \\
Specific heat $(\mathrm{J} /(\mathrm{kgK}))$ & 875 & 427 \\
\hline \hline
\end{tabular}


Aluminum is a typical plastic material. Johnson cook (J-C) model is used to characterize its plastic deformation stage [23], and J-C model is often characterized as shown:

$$
\sigma=\left(A+B \bar{\varepsilon}^{p n}\right)\left(1+C \ln \frac{\dot{\bar{\varepsilon}}^{p n}}{\dot{\bar{\varepsilon}}_{0}}\right)\left[1-\left(\frac{T-T_{0}}{T_{\text {melt }}-T_{0}}\right)^{m}\right]
$$

where $\sigma$--flow stress (MPa); $\varepsilon$-- Effective plastic strain; $\dot{\varepsilon}$-- Effective plastic strain rate; $\dot{\varepsilon}_{0}$-- Reference plastic strain rate; $T$-- Environment temperature $\left({ }^{\circ} \mathrm{C}\right) ; T_{\mathrm{m}}$-- Melting point temperature of the material; $A$-- Yield stress of the material $(\mathrm{MPa}) ; B$-- Work hardening parameters of the material $(\mathrm{MPa}) ; C$-- Strain rate enhancement index; $m$-- Temperature change rate index; $n$-- Strain hardening index.

Johnson-cook fracture criterion and damage parameter $D$ was used to judge the material removal. $D$ was set to be 1 , and the unit was separated and removed. The expression is

$$
D=\sum \frac{\Delta \varepsilon}{\varepsilon^{f}}
$$

where $\varepsilon^{f}$-- failure strain; $\Delta \varepsilon$-- The effective plastic strain increment under load unit increase.

Johnson-cook fracture criterion [24], the calculation formula of equivalent plastic strain is

$$
\varepsilon^{f}=\left[d_{1}+d_{2} \exp \left(\mathrm{d}_{3} \frac{\delta_{m}}{\bar{\delta}}\right)\right]\left(1+d_{4} \ln \frac{\dot{\varepsilon}}{\dot{\varepsilon}_{0}}\right)\left[1+d_{5}\left(\frac{T-T_{\mathrm{r}}}{T_{\mathrm{m}}-T_{\mathrm{r}}}\right)\right]
$$

where $\varepsilon^{f}$-- equivalent plastic strain; $\delta_{m}$-- Average value of positive pressure (MPa); $\delta$-- Effective stress (MPa); $d_{1}-d_{5}$-- material failure parameters. The following Table 2 shows the J-C model and $\mathrm{J}-\mathrm{C}$ fracture model parameters of 2024 aluminum alloy.

Table 2 Some parameters of matrix J-C model and J-C fracture model [25]

\begin{tabular}{cc}
\hline \hline$A(\mathrm{MPa})$ & 369 \\
\hline$B(\mathrm{MPa})$ & 684 \\
$C$ & 0.0083 \\
$m$ & 1.7 \\
$n$ & 0.73 \\
$d_{1}$ & 0.112 \\
$d_{2}$ & 0.123 \\
$d_{3}$ & 1.5 \\
$d_{4}$ & 0.007 \\
$d_{5}$ & 0 \\
$\left.T_{\mathrm{m}}{ }^{\circ} \mathrm{C}\right)$ & 502 \\
$\left.T_{\mathrm{r}}{ }^{\circ} \mathrm{C}\right)$ & 20
\end{tabular}

The tool is set as analytical rigid body in the simulation. The cutting edge radius is $10 \mu \mathrm{m}$, the rake angle is $7^{\circ}$ and the rake angle is $20^{\circ}$ respectively. The contact mode is face to face contact, and the Coulomb friction model is adopted, with the friction coefficient of 0.35 [6]. The bottom of the matrix and the upper right part of the tool are constrained by the boundary.

\subsection{Criteria for chip separation}

The characteristics of aluminum matrix also adopt $\mathrm{J}-\mathrm{C}$ and $\mathrm{J}-$ C fracture models [26], adopt brittleness removal criteria for $\mathrm{SiC}$ particles, and select a tensile stress standard to judge, and its characterization is as follows:

$$
\max \left(\delta_{1}, \delta_{2}, \delta_{3}\right)=\delta_{0}
$$

where $\delta_{1}, \delta_{2}, \delta_{3}$-- principal stress (MPa); $\delta_{0}$-- crushing stress of $\mathrm{SiC}$ material (MPa).

In the failure criterion of Brittle materials, the standard model of energy is used to measure the cracking and crack expansion of silicon carbide. The crack displacement during failure can be expressed by

$$
u_{n 0}=2 G_{f}^{l} / \delta_{m}^{l}
$$

where $u_{\mathrm{n} 0}$-- Nominal displacement $(\mu \mathrm{m}) ; G_{f}^{I}$-- mode I fracture energy $\left(\mathrm{J} / \mathrm{m}^{2}\right) ; \delta_{m}^{I}$-- critical stress of mode I fracture (MPa). The stress retention model is used to describe crack propagation due to shear stress. The shear modulus $G_{\mathrm{c}}$ after cracking can be calculated by the following formula

$$
G_{c}=\left(1-\frac{e_{n n}^{c k}}{e_{\max }^{c k}}\right)^{p} G
$$

where $p, e_{\max }^{c k}--$ material parameters; $G$-- Shear modulus of the material (MPa); $e_{n n}^{c k}-$ Crack propagation strain. The brittle fracture parameters of $\mathrm{SiC}$ materials standards as shown in Table 3.

Table 3 Parameters of material brittleness removal [26], [27]

\begin{tabular}{cccc}
\hline \hline$\delta_{0}$ & $G_{f}^{l}$ & $p$ & $e_{\max }^{c k}$ \\
\hline 1500 & 30 & 1 & 0.001 \\
\hline \hline
\end{tabular}

2.4.The relationship between experiment and simulation

In the experiment, the maximum milling depth was $50 \mu \mathrm{m}$, which was very small compared with the tool diameter of $1000 \mu \mathrm{m}$, as shown in Fig. 3. In this case, the effect of helix Angle on chip formation and cutting force can be ignored. Therefore, the 3D micro-milling process is simplified to 2D micro-orthogonal cutting path. It is assumed that the uncut thickness is the same as the chip thickness. (a) Schematic diagram of a two-dimensional milling process; (b) The relationship between milling and orthogonal milling models.

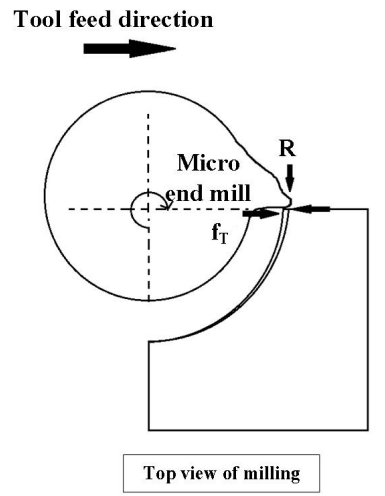


(b)

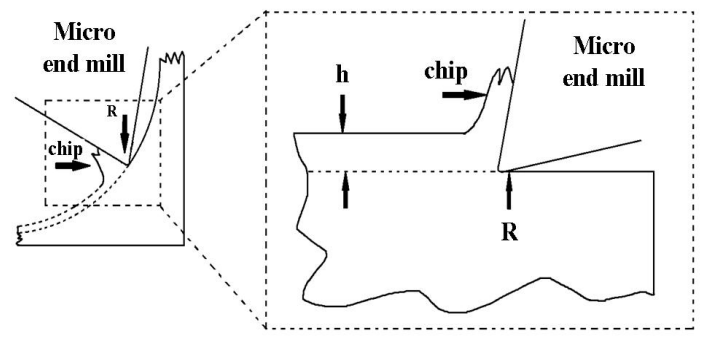

Relationship between two dimensional orthogonal diagram and milling

Figure 3. Schematic Diagram of milling process (a) Overview diagram of milling; (b) Diagram of the relationship between milling and the orthogonal cutting model

\subsection{Analysis of cutting mechanism and results}

In the simulation, the cutting speed is set to $37.68 \mathrm{~m} / \mathrm{min}$, which is equivalent to the spindle speed of $12000 \mathrm{r} / \mathrm{min}$, and the milling depth is $40 \mu \mathrm{m}$. After the simulation, the particle removal and surface defects are analyzed, it can be founded that the removal forms of milling particles are also different at different positions, as shown in Fig. 4.
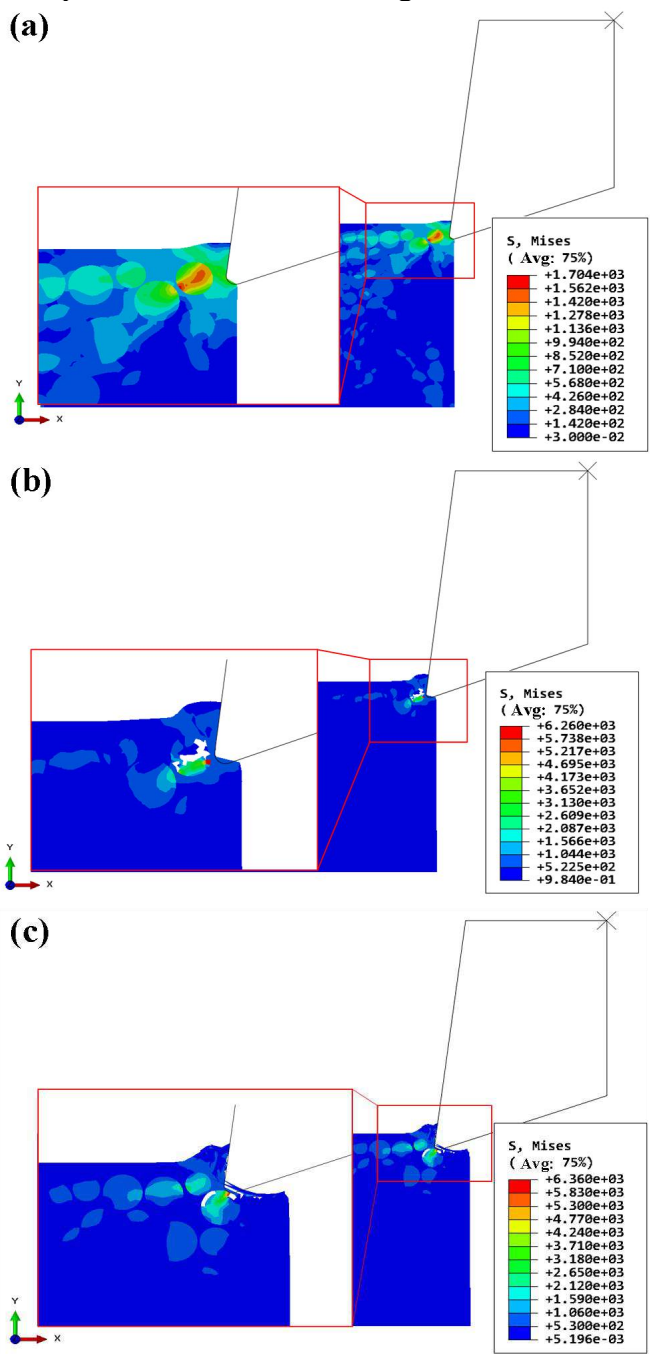

(d)
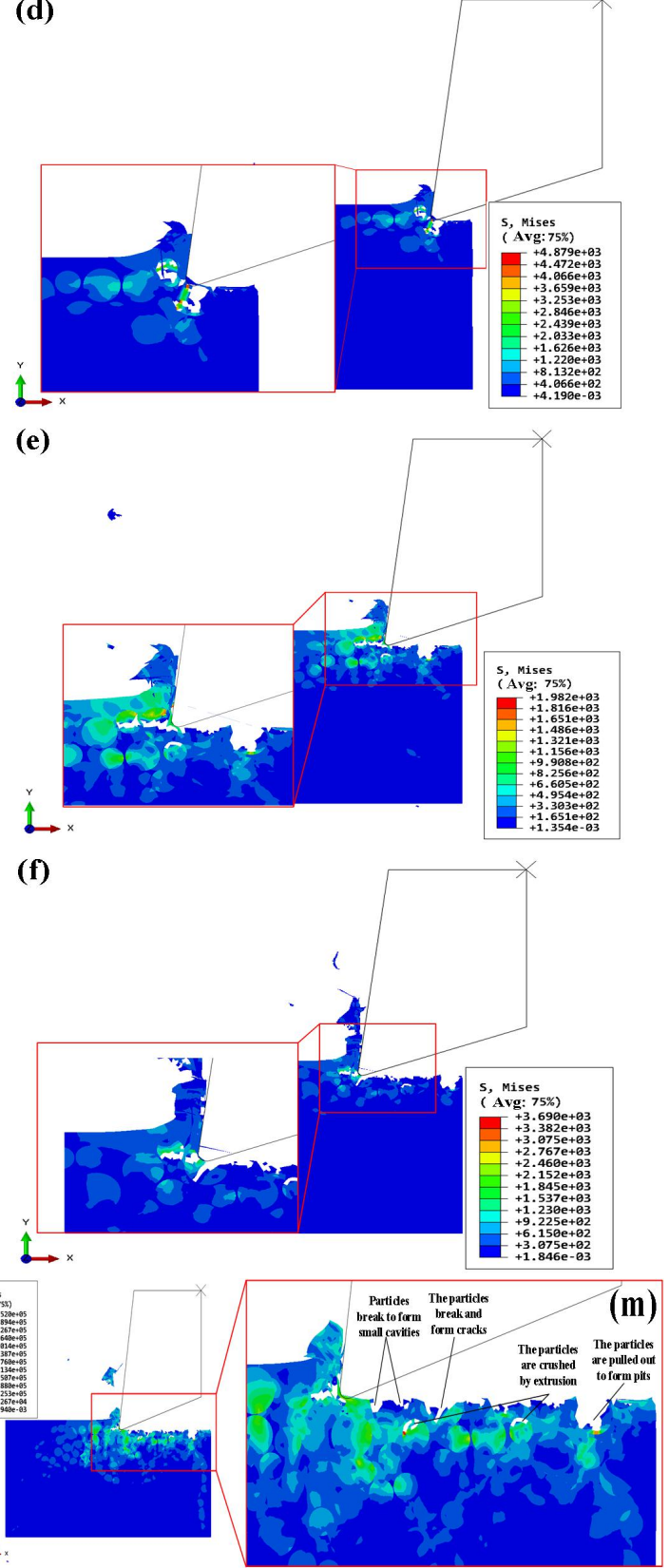

Figure 4. Removal mode and surface morphology of particles in simulation (a)-(l) $V_{C}=37.68 \mathrm{~m} / \mathrm{min}, a_{p}=\mathbf{4 0} \mu \mathrm{m}$ particle removal mode; $(\mathrm{m}) V_{C}=37.68 \mathrm{~m} / \mathrm{min}$, $a_{p}=40 \mu \mathrm{m}$ surface morphology

It can be seen from Fig. 4 that when micro-milling $\mathrm{SiCp} / \mathrm{Al}$ composites, the main removal forms of particles are peeling, shedding, crushing and pressing, because the particle size and position are randomly selected when the model is established, the removal of particles is also different when the tool is milling different positions of particles.

In Fig. 4 (c), (d) when milling the upper part of the particle, part of the interface between the particle and the aluminum matrix is destroyed, the point where the particle contacts the front Angle of the blade and the part above the point is removed, and the following part is pressed into the matrix. 
The tool first cuts the aluminum matrix, and the Al matrix is plastically deformed. With the milling, the tool nose gradually approaches the particles, which makes the constraint between the particles and the matrix fail, and the aluminum matrix is plastically removed, the tool continues to milling particles, resulting in an increase in the stress on the upper part of the particles. When the milling stress is greater than the strength limit value of the particle material, the particles will produce brittle deformation. With the progress of milling, the deformation will continue to expand, the upper part of the particle is peeled off, and cracks and pits are generated on the surface of the workpiece.

In Fig. 4(a), (b), when the tool milling particles near the middle position, under the extrusion of the tool, most of the particle interface fails, A small part of the particles are directly pressed into the matrix. When the tool is milling the middle part of the particle, due to the front and rear extrusion of the particle and the tool, the aluminum matrix produces plastic deformation and is extruded to the upper and lower parts of the particle. At this time, the constraint fails and changes into the milling process of silicon carbide particles, when the milling stress is greater than the strength limit value of the particle material, the brittle deformation of the particle is removed.

Fig. 4(d), (e) show the situation of the lower half and bottom of the milling particle with the cutter. The interface fails completely and the particle is directly pulled out. Under the cutting of the tool, the particles are squeezed with each other, which will also break and remove the particles. When the tool is milling the lower half of the particle, the constraint gradually fails when the rake angle of the tool contacts with the particle. With the milling of the tool, the milling stress is greater than the strength limit value of the particle material, and the interface fails sharply, the lower half of the particles is crushed, most of the particles are pulled out, and larger pits are generated on the processed surface. When the tool is milling the bottom of the particle, the contact surface near the bottom of the particle and the matrix will cause constraint failure when the particle is in contact with the front angle of the tool. With the milling of the tool, it can be seen that the actual cutting position of tool nose is aluminum matrix, so the cutting position of tool edge diameter is aluminum matrix. With the progress of milling, particles are completely removed and the processing surface quality is better.

In Fig. 4(m), it can be seen that in the cutting process, the stress concentration area is mainly the plane where the matrix and the particle contact, while the irregular stress distribution area is mainly the location area where the tool interacts with the particle and the matrix material. It can be judged that stress concentration and irregular stress distribution lead to particle breakage, peeling, shedding, the main causes of extrusion and surface defects.

The particle removal and surface defects after the simulation are shown in Fig. 5.

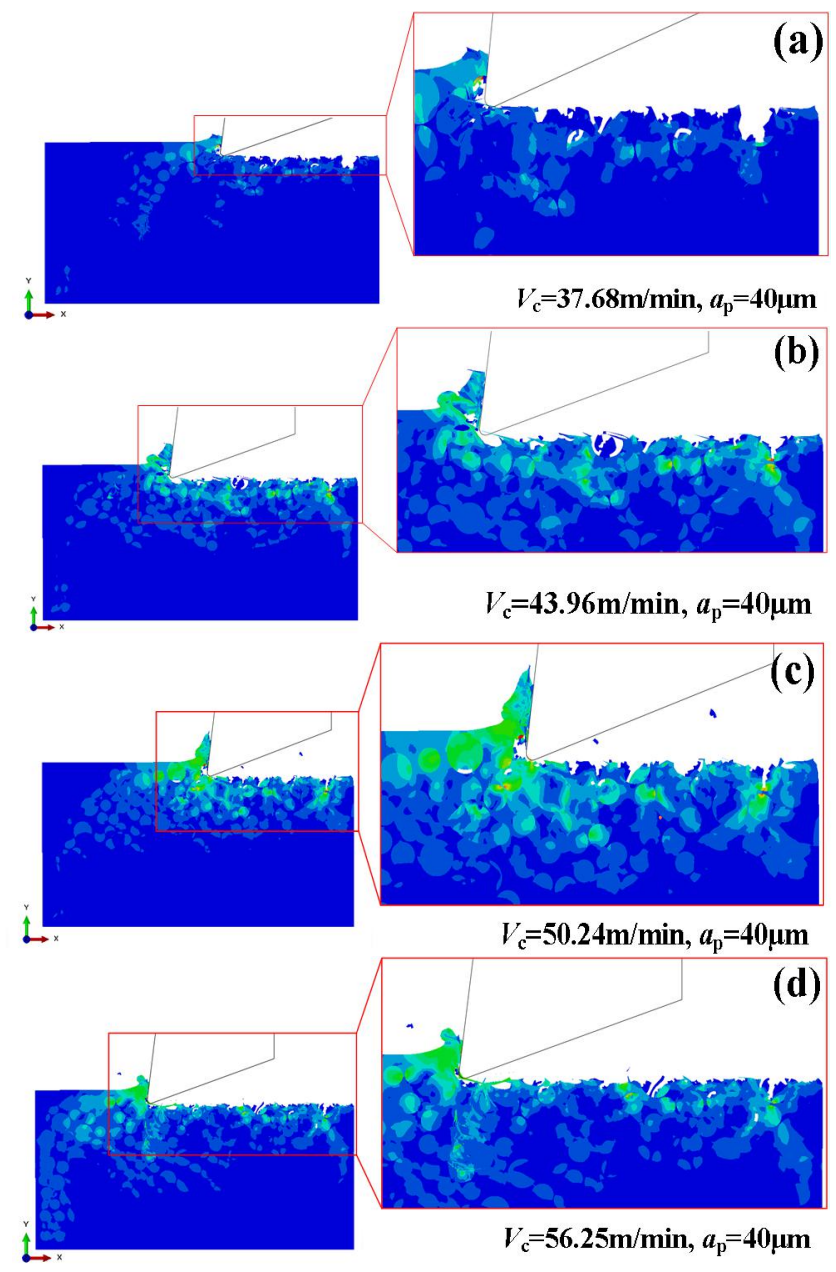

Figure 5. Morphology of $\mathrm{SiCp} / 2024 \mathrm{Al}$ composite micromachined surface

It can be seen from Fig. 5, as the cutting speed increases, the cracks and defects of particles decrease, and the surface quality of the material becomes better. This is mainly because as the cutting speed increases, the cutting stress in the system increases, so the strain rate increases. According to the J-C failure criterion, the increase of stress and strain rate makes the Matrix easy to remove. For Silicon carbide particles, when the tool is milling particles, the cutting stress on the particles increases rapidly, but the cutting speed increases, resulting in a decrease in the time used to cut particles. Compared with the low cutting speed, the interaction time between tool and particle is shorter, and the stress transfer time is shorter, thus reducing crack propagation and defect formation. Therefore, in high-speed cutting, the surface defects of the material are less and the surface morphology is smoother.

\section{Experimental study on micro milling}

\subsection{The experimental scheme}

The experiment mainly studies and analyzes the surface defects formed by PCD end mill milling groove processing particle reinforced aluminum matrix composite $\mathrm{SiCp} / \mathrm{Al}$, and the influence of milling dosage on the surface quality. The material used in the experiment is $\mathrm{SiCp} / \mathrm{Al}$ composite 
material composed of A12024 aluminum alloy and $\mathrm{SiC}$ particles. The volume fraction of particles is $60 \%$. The particle part is mainly composed of $20 \mu \mathrm{m}$ and $60 \mu \mathrm{m}$ particles with an average size of $40 \mu \mathrm{m}$. Diamond end mill is selected as the experimental tool. The tool diameter is $1 \mathrm{~mm}$, the edge radius is $10 \mu \mathrm{m}$, the rake angle is $7^{\circ}$ and the rake angle is $20^{\circ}$.

The experiment was carried out on the Carver400 of Beijing carved vertical machining center. The experimental site is shown in Fig. 6. The surface roughness value of material cutting is measured by real color scanning microscope. The surface micro-morphology of material cutting is observed by Zeiss SIGMA 500 field emission scanning electron microscope, and the experimental equipment is shown in Fig. 7.

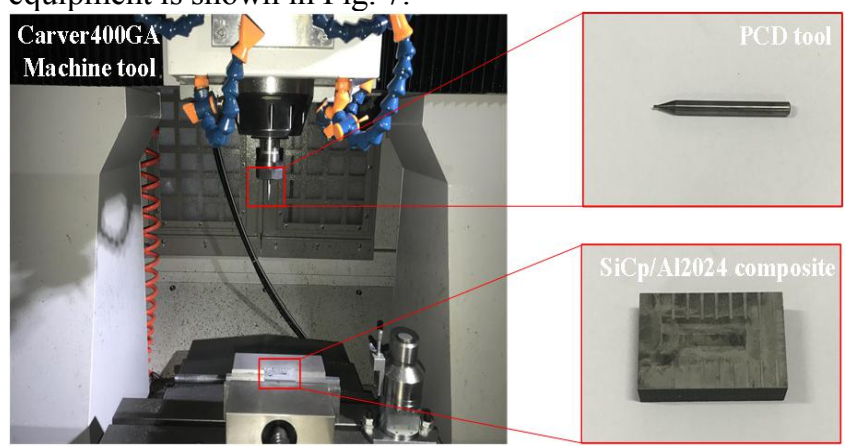

FIGURE 6. Experimental site
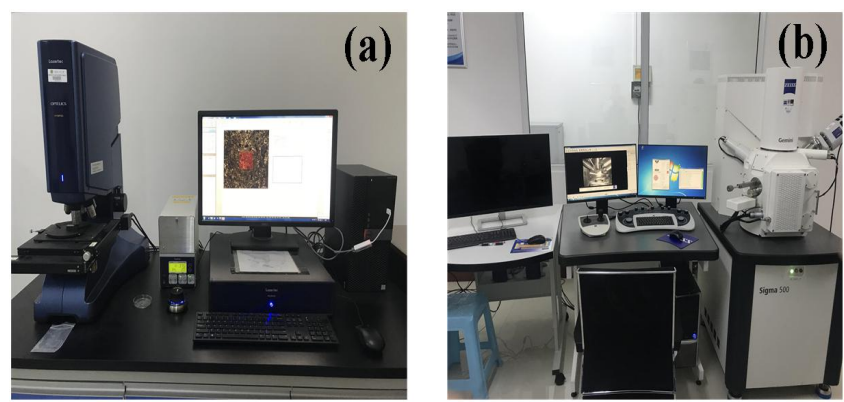

Figure 7. Experimental measurement equipment (a) True color confocal microscope; (b) Zeiss SIGMA 500 field emission scanning electron microscope

This micro milling experiment mainly studies the influence of process parameters on surface roughness. The processing parameters used in milling test as shown in Table.4.

Table 4 Parameter selection of orthogonal test

\begin{tabular}{ccc}
\hline \hline Spindle speed(r/min) & Feed rate(mm/min) & Milling depth $(\mu \mathrm{m})$ \\
\hline 12000 & 6 & 20 \\
14000 & 8 & 30 \\
16000 & 10 & 40 \\
18000 & 12 & 50 \\
\hline \hline
\end{tabular}

Orthogonal experiments are adopted to judge the influence degree of each parameter so as to optimize the parameters. According to the spindle rotation speed, feed speed and milling depth of the three process parameters, a three-factor and four-level experiment is designed, ignoring the interaction, L16 orthogonal experiment table is selected, and the process parameters and their levels are shown in Table V.

Table 5 Process parameters and their levels

\begin{tabular}{cccccc}
\hline & & \multicolumn{5}{c}{ level } \\
\cline { 3 - 6 } Parameters & & 1 & 2 & 3 & 4 \\
\hline Spindle speed $N(\mathrm{r} / \mathrm{min})$ & $\mathrm{A}$ & 12000 & 14000 & 16000 & 18000 \\
Feed rate $V_{f}(\mathrm{~mm} / \mathrm{min})$ & $\mathrm{B}$ & 6 & 8 & 10 & 12 \\
Milling depth $a_{p}(\mu \mathrm{m})$ & $\mathrm{C}$ & 20 & 30 & 40 & 50 \\
\hline \hline
\end{tabular}

The schematic diagram of micro-milling is shown in Fig. 8. Under the action of load, the sharp milling edge is cut into the surface of the material at a certain speed, causing the plastic deformation of the latter and forming a milling groove on its surface.

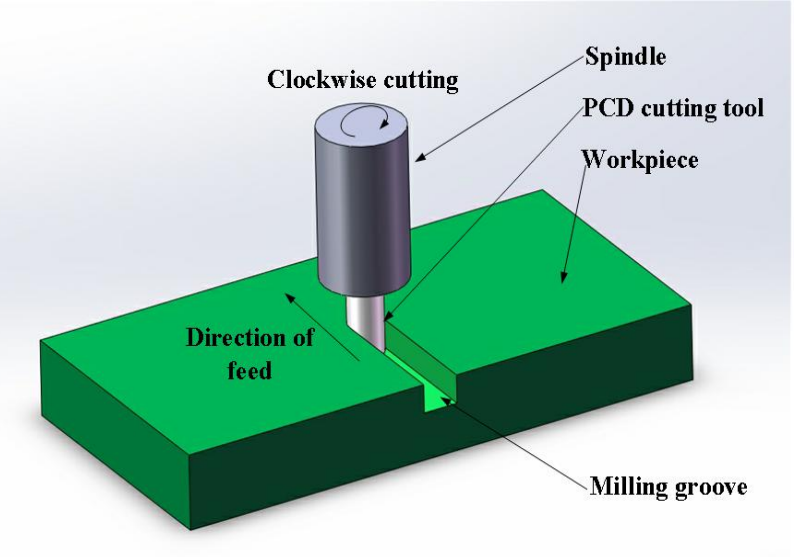

Figure 8. Schematic diagram of milling

\subsection{Analysis of experimental results}

Due to the existence of reinforced silicon carbide particles in particle reinforced aluminum matrix composites, the effects of the micro-morphology, formation rule and cutting parameters on the machined surface quality of the composites are different from the one-way material of the workpiece.

The micro-morphology of the milling surface of particle reinforced aluminum matrix composites was detected by real color scanning microscope, and four groups of experiments with obvious and representative surface micro-morphology characteristics were selected for analysis, the threedimensional features of surface topography are shown in Fig 9 . 


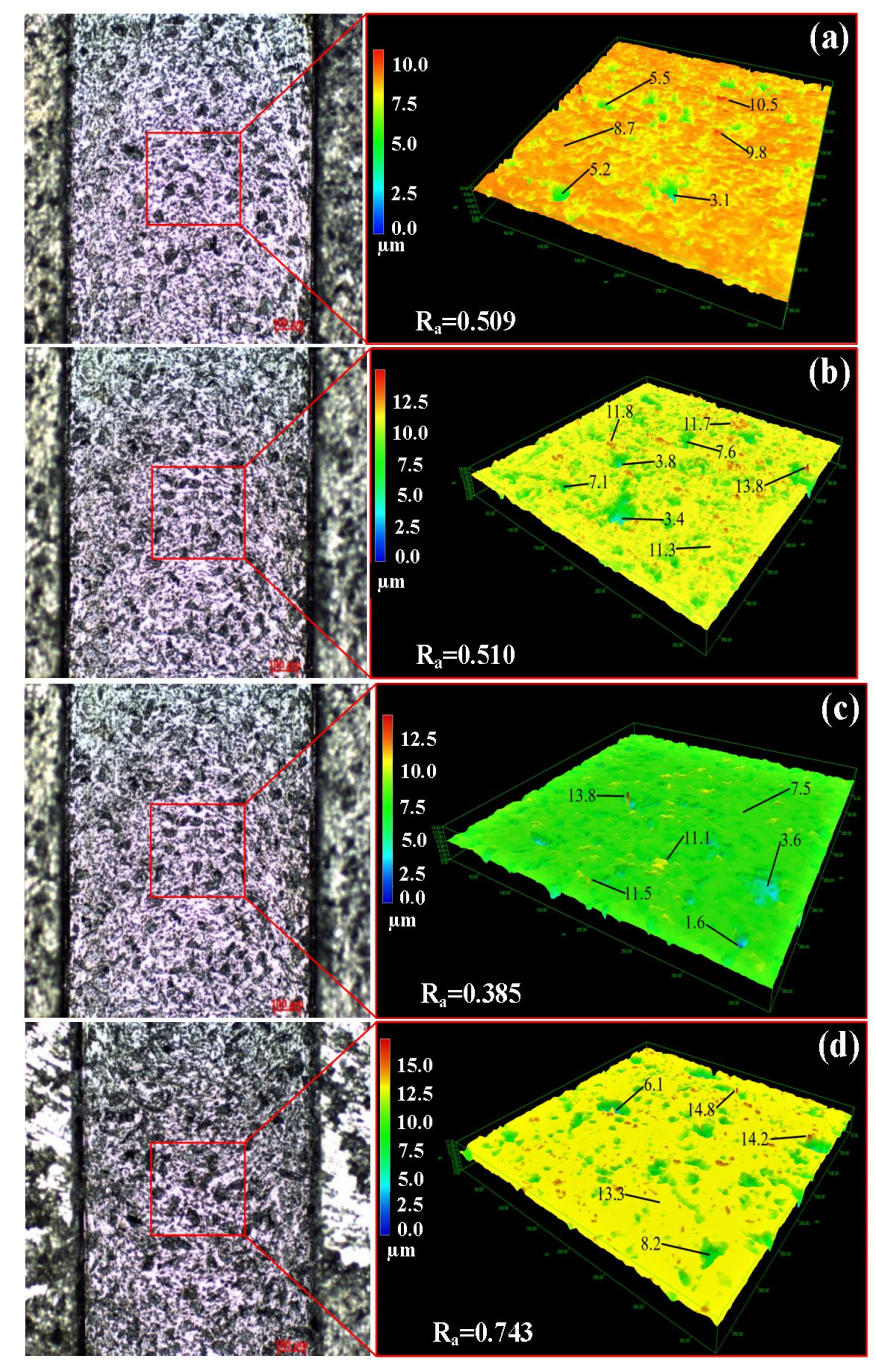

Figure 9. Three-dimensional feature map of surface morphology; (a) $N=14000$ $\mathrm{r} / \mathrm{min}, V_{f}=\mathbf{0 . 0 1 2} \mathrm{m} / \mathrm{min}, a_{p}=\mathbf{5 0} \mu \mathrm{m}$; (b) $N=\mathbf{1 4 0 0 0} \mathrm{r} / \mathrm{min}, V_{f}=\mathbf{0 . 0 1} \mathrm{m} / \mathbf{m i n}, a_{p}=50$ $\mu \mathrm{m}$; (c) $N=16000 \mathrm{r} / \mathrm{min}, V_{f}=0.006 \mathrm{~m} / \mathrm{min}, a_{p}=40 \mu \mathrm{m}$; (d) $N=18000 \mathrm{r} / \mathrm{min}$, $V_{f}=\mathbf{0 . 0 1 2} \mathbf{m} / \mathrm{min}, a_{p}=\mathbf{2 0} \boldsymbol{\mu m}$

The three-dimensional features according to the observed surface topography are shown in Fig. 9. It can be seen that the machining surface in Fig. 9 (c) is relatively smooth, that is, when the spindle speed is $16000 \mathrm{r} / \mathrm{min}$, the feed speed is $6 \mathrm{~mm} / \mathrm{min}$ and the milling depth is $40 \mu \mathrm{m}$, the surface morphology of the material is relatively good. $\mathrm{R}_{\mathrm{a}}$ is 0.385 $\mu \mathrm{m}$.

There are two main reasons: (1) because the milling thickness is greater than the minimum cutting thickness of the aluminum matrix, so the removal effect of the aluminum matrix is better, and the resistance to the milling tool is reduced at the same time, so that the surface is relatively smooth; (2) the milling volume of particles is small and the broken particles are few, so the milling force is small and the amplitude of the spindle is small, which makes the surface quality better. The feed per tooth will increase, the milling volume of aluminum matrix and particles will increase in unit time, the material size effect will be weakened, and most of the particles will be broken and removed, when the spindle speed remains unchanged and the feed speed increases. The broken tiny particles will scratch the surface under the extrusion of the tool. The formation of small cavities and scratches is shown in Fig. 9 (a), (b) and (d), the surface defects increase. In addition, a large number of scratches and small cavities were also found on the surface of the material by scanning electron microscopy (SEM), as shown in Fig. 10 (a).

Large pits and cracks appear in Fig. 9 (a) and (b), because the milling volume of aluminum matrix and particles increases per unit time, resulting in the increase of milling force, the vibration of the spindle is intensified, and the particle size of the material is relatively large in the experiment. It will appear cracks and cavities caused by particles being crushed and broken, as well as defects such as pits caused by particles being pulled out, when the milling depth is deep enough or the feed beam per tooth,

The micro-morphology of the milling surface of particle reinforced aluminum matrix composite was detected by Zeiss SIGMA 500 field emission scanning electron microscope, and the surface defects of the material were shown in Fig. 10.

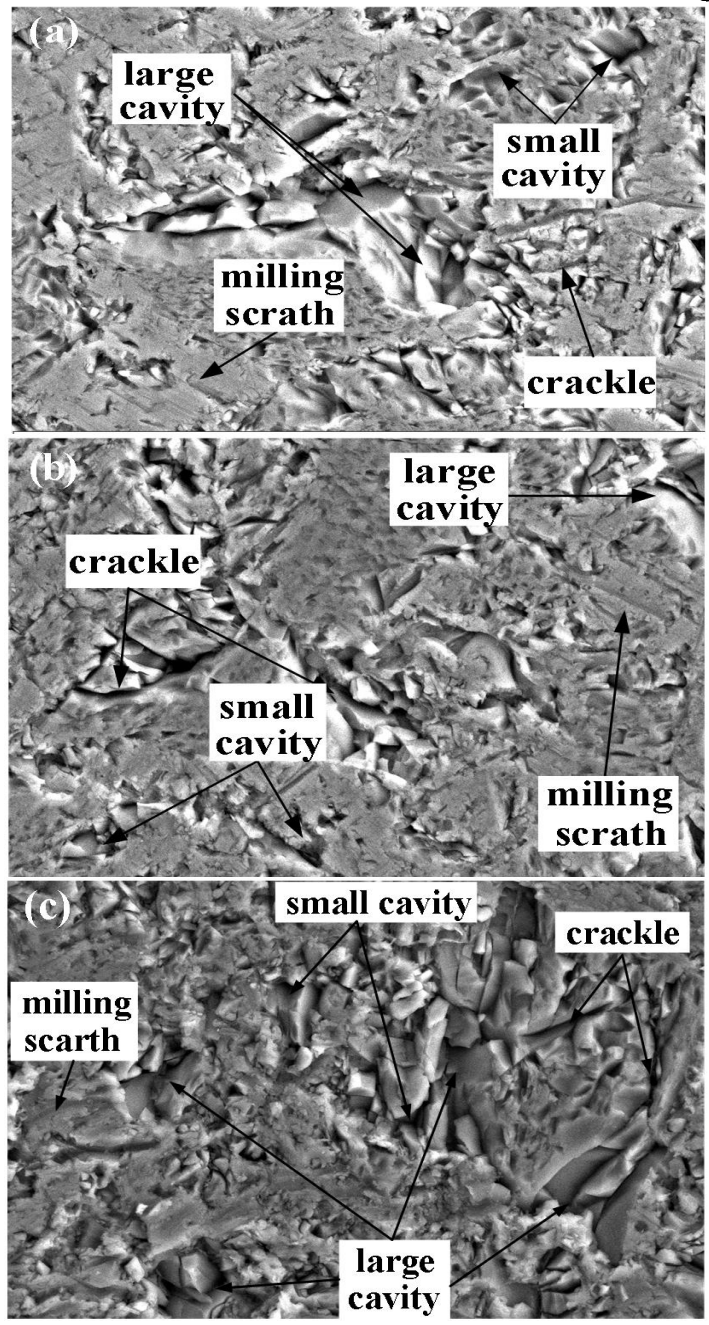




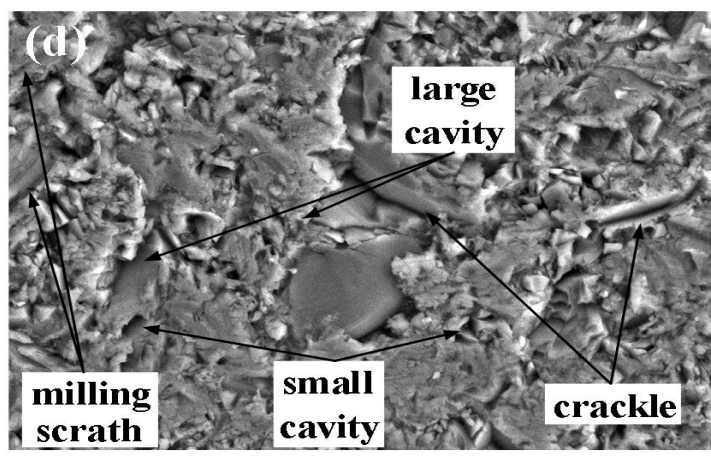

Figure 10. Material surface defect detection with the same milling depth and different feed per tooth; (a) $f_{z}=0.5 \mu \mathrm{m}, a_{p}=40 \mu \mathrm{m}$; (b) $f_{z}=0.571 \mu \mathrm{m}, a_{p}=40 \mu \mathrm{m}$; (c) $f_{z}=0.625 \mu \mathrm{m}, a_{p}=40 \mu \mathrm{m}$; (d) $f_{z}=0.667 \mu \mathrm{m}, a_{p}=40 \mu \mathrm{m}$

The surface roughness values corresponding to the four sets of cutting parameters (a), (b), (c) and (d) are shown in Fig. 11 in turn.

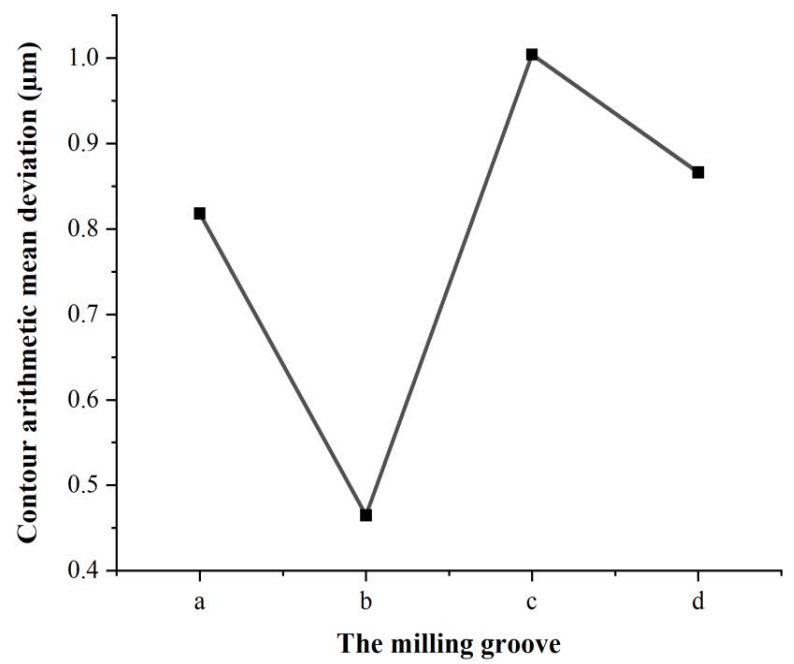

Figure 11. Surface roughness value corresponding to (a), (b), (c) and (d)

The detection energy spectrum of the surface of the processed material is shown in Fig. 12, while the spindle speed is $12000 \mathrm{r} / \mathrm{min}$, the feed speed is $0.006 \mathrm{~m} / \mathrm{mim}$ and the milling depth is $40 \mu \mathrm{m}$.

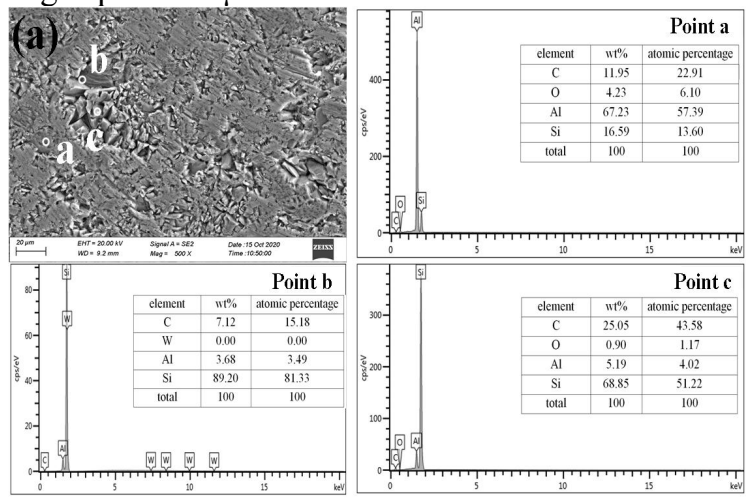

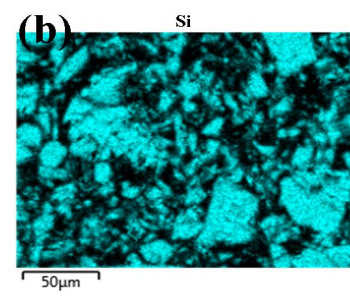
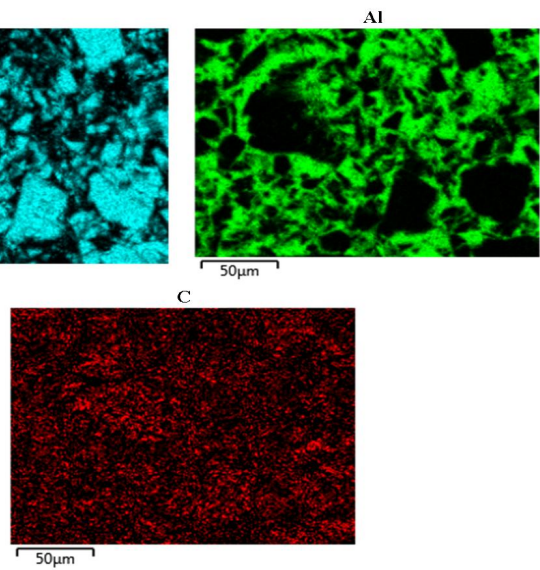

Figure 12. Composite material surface material detection diagram (a) Surface material point detection; (b) Surface detection surface scanning

Fig. 10 shows the cracks and cavities generated by the particles being crushed and broken during the cutting process of composite materials, the scratches caused by the crushed particles being crushed, and the holes caused by the particles being pulled out, etc, these defects have been clearly displayed in the finite element simulation model, and the experimental pictures verify the correctness of the finite element simulation model to some extent.

Combining Fig. 10 and Fig. 11, these can be founded that when the feed per tooth increases, the surface defects of the processed material first increase rapidly, then decrease rapidly and then increase slowly, and the surface quality first increases rapidly, then decreases rapidly and then increases slowly. Milling process, the milling depth unchanged, with the increase of each tooth feeding, surface roughness parameter $R_{a}$ to decrease rapidly after increase rapidly, it shows that when the $f_{z}$ is $0.5 \mu \mathrm{m}$ is likely to occur the phenomenon of plough and $\mathrm{R}_{\mathrm{a}}$ value is bigger. The increase of feed rate per tooth leads to the increase of milling volume per unit time. At the same time, milling force and tool vibration increase, which makes the surface defects increase. The falling particles will roll and slide along with the tool on the machined surface, which will cause scratches on the workpiece surface, make the surface quality worse.

With the increase of each tooth feed, the milling force increases, the friction is serious, the temperature rises rapidly, the residual aluminum matrix on the surface of the workpiece melts and binds to the material surface, resulting in the decrease of surface roughness.

The voids and cracks in Fig. 10 are randomly distributed, and Fig. 12 shows the energy spectrum of material element detection obtained by scanning e-sports, which can prove this problem. According to the detection results in Fig. 12 (a), the Si element contained in point $\mathrm{b}$ is $89.20 \%$, the $\mathrm{Al}$ element is $3.68 \%$, and the Si element contained in point c is $68.85 .20 \%$. The $\mathrm{Al}$ element is $5.19 \%$. According to the detection results in Fig.12 (b), the position of point b is $\mathrm{SiC}$ particles, which indicates that the particles are broken and pulled out from a 
part, point $\mathrm{b}$ is the hole caused by the particles being pulled out. According to the detection result, the $\mathrm{Al}$ element contained in point a is $67.23 \%$ and the Si element is $16.59 \%$. In combination with Fig. 12 (b), an aluminum matrix can be attached to the $\mathrm{SiC}$ particles. This is because the formed aluminum matrix chip cannot be completely removed during milling, resulting in a small amount of residue melting and remaining on the surface of the workpiece under high temperature conditions. With the progress of milling, the friction heat generation increases, as a result, more aluminum matrix remains on the processing surface after melting, surface defects of materials can be made up and surface quality can be improved.

\section{Orthogonal experimental analysis and parameter optimization}

The evaluation method of surface roughness selected in this paper is the centerline method, which is mainly used for $R_{a}$ evaluation. $R_{a}$ represents the arithmetic mean of the absolute value of the distance of contour offset from the undulating center line along the measured direction within the sampling length, and its calculation formula is shown:

$$
\mathrm{R}_{a}=\frac{1}{n} \sum_{i=1}^{n}\left|y_{i}\right|
$$

where $y_{i}$-- represents the distance between the point on the contour line and the center line in the measured direction.

In order to analyze the influence of spindle speed, feed speed and milling depth on surface quality, L16 orthogonal experiment table is selected to plan orthogonal experiment. Combined with the measurement results in the previous section, the process parameters determined, the level and its measurement results are shown in Fig. 13.

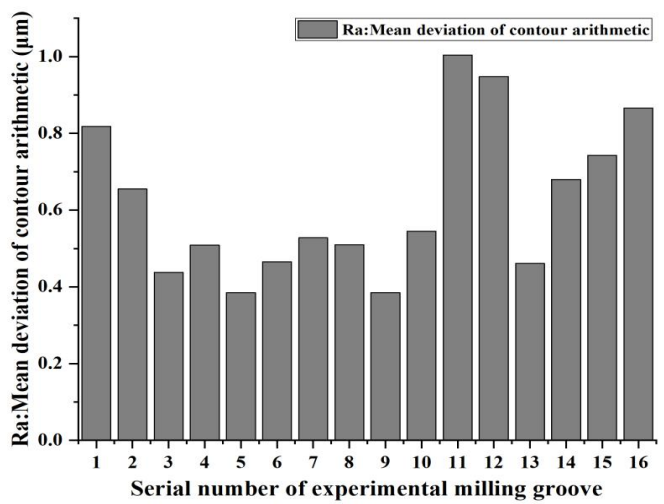

Figure 13. Measurement results of surface roughness of milling groove

According to the measurement results, the range analysis of the arithmetic mean deviation of contour is shown in Table 6 .
Table 6 Analysis of surface roughness range

\begin{tabular}{cccc}
\hline \hline Experiment number & $\begin{array}{c}\text { Spindle speed } \\
\mathrm{A}(\mu \mathrm{m})\end{array}$ & $\begin{array}{c}\text { Feed rate B } \\
(\mu \mathrm{m})\end{array}$ & $\begin{array}{c}\text { Milling depth } \\
\mathrm{C}(\mu \mathrm{m})\end{array}$ \\
\hline $\mathrm{K}_{1}$ & 2.42 & 2.049 & 3.097 \\
$\mathrm{~K}_{2}$ & 1.888 & 2.345 & 2.787 \\
$\mathrm{~K}_{3}$ & 2.882 & 2.713 & 2.013 \\
$\mathrm{~K}_{4}$ & 2.75 & 2.833 & 2.043 \\
$\mathrm{k}_{1}$ & 0.605 & 0.51225 & 0.77425 \\
$\mathrm{k}_{2}$ & 0.472 & 0.58625 & 0.69675 \\
$\mathrm{k}_{3}$ & 0.7025 & 0.67825 & 0.50325 \\
$\mathrm{k}_{4}$ & 0.6875 & 0.70825 & 0.5015 \\
Range & 0.2305 & 0.196 & 0.27275 \\
Primary and & Milling depth $>$ Spindle speed $>$ Feed speed \\
Optimal levels & A & $\mathrm{B}_{2}$ & $\mathrm{C}_{3}$ \\
\hline \hline
\end{tabular}

The greater the range, the greater the influence degree of this factor. It can be seen from Table VI that the milling depth has the greatest influence on the average deviation $R_{a}$ of contour arithmetic, followed by the spindle speed and the feed speed. The optimal process parameter combination of contour arithmetic average deviation $R_{a}$ is mainly the shaft speed $14000 \mathrm{r} / \mathrm{min}$, feed speed $6 \mathrm{~mm} / \mathrm{min}$ and milling depth $40 \mu \mathrm{m}$, and the influence degree of each parameter is very small, it shows that the surface morphology characteristics of the processed surface are relatively consistent. When these parameters are selected for milling, the average deviation $\mathrm{R}_{\mathrm{a}}$ of the surface contour arithmetic obtained is the smallest, and the surface defects are the least as shown in Fig. 14.

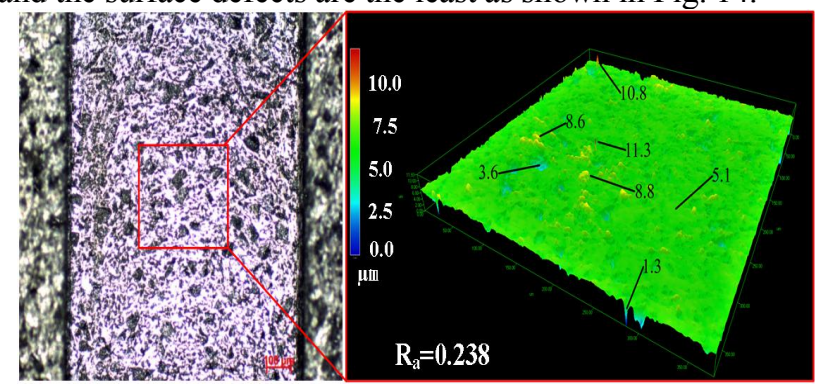

Figure 14. Surface 3D morphology characteristics of $N=14000 \mathrm{r} / \mathrm{min}, V_{f}=\mathbf{0 . 0 0 6}$ $\mathbf{m} / \mathbf{m i n}$ and $a_{p}=\mathbf{5 0 \mu m}$

Through the optimization of cut parameters, it can be found that when using diamond end mill with smaller diameter and blade diameter to process large particle highvolume silicon carbide metal composite. Milling parameters such as spindle speed $14000 \mathrm{r} / \mathrm{min}$, feed speed $0.006 \mathrm{~m} / \mathrm{min}$ and milling depth $40 \mu \mathrm{m}$ were selected. The surface quality was good, and the average arithmetic deviation of surface rounghness $\mathrm{R}_{\mathrm{a}}$ is $0.238 \mu \mathrm{m}$. 


\section{Conclusion}

From the simulation and experimental results, these were concluded that:

When micro-milling Silicon Carbide aluminum matrix metal composites, the main removal forms of particles are peeling, shedding, crushing and pressing, and the removal of particles is also different at different positions of milling particles.

During the milling process, keep the spindle speed and feed speed unchanged, and increase the milling depth eventually leads to the deterioration of the surface quality of the material being processed.

The milling depth is kept constant during the milling process. With the increase of each tooth feed, the surface roughness value decreases rapidly and then increases rapidly. This indicates that ploughing may occur when $f_{z}$ is $50 \mu \mathrm{m}$, so the surface roughness value is large. With the increase of each tooth feed, the milling force increases, the friction is serious, and the temperature rises rapidly, which leads to the melting and solidification of the residual aluminum metal on the workpiece surface, leading to better surface quality.

During the cutting process of composite materials, cracks and cavities caused by particles being crushed and broken, scratches caused by crushed particles being crushed, holes caused by particles being pulled out, etc. Rolling and sliding of shedding particles on the processing surface under the action of cutting tools is one of the important reasons for scratches and pits on the surface of workpieces.

Through the optimization of milling parameters, it is found that the milling depth has the greatest influence on the surface roughness $\mathrm{R}_{a}$, followed by the spindle speed and feed speed when the milling tool with small cutting edge radius is used to mill the $\mathrm{SiCp} / \mathrm{Al}$ composite with large particles. The optimal combination of process parameters of the surface roughness $R_{a}$ is mainly the shaft speed 14000 $\mathrm{r} / \mathrm{min}$, the feed speed is $6 \mathrm{~mm} / \mathrm{min}$ and the milling depth is 40 $\mu \mathrm{m}$; At this time, the surface quality is better, $\mathrm{R}_{a}$ is $0.238 \mu \mathrm{m}$.

\section{Ethical Approval}

This research project has been approved by the Ethics Committee of Liaoning University of Technology.

\section{Consent to Participate}

I solemnly declare that the paper "Research on Micro Milling Mechanism and Surface Roughness of High Volume Fraction $\mathrm{SiCp} / \mathrm{Al}$ Composites" presented by us is the result of our research. This paper does not contain any work published or written by any other individual or group, except for the content specifically noted and cited in the paper. I fully realize that the legal consequences of this statement shall be borne by me.

\section{Consent to Publish The Author confirms}

That the work described has not been published before; That it is not under consideration for publication elsewhere; That its publication has been approved by all co-authors, if any;

That its publication has been approved by the responsible authorities at the institution where the work is carried out.
The Author agrees to publication in the Journal indicated below and also to publication of the article in English by Springer in Springer's corresponding English-language journal. The copyright to the English-language article is transferred to Springer effective if and when the article is accepted for publication. The author warrants that his/her contribution is original and that he/she has full power to make this grant. The author signs for and accepts responsibility for releasing this material on behalf of anyand all co-authors. The copyright transfer covers the exclusive right to reproduce and distribute the article, including reprints, translations, photographic reproductions, microform, electronic form or any other reproductions of similar nature. After submission of the agreement signed by the corresponding author, changes of authorship or in the order of the authors listed will not be accepted by Springer. Journal: The International Journal of Advanced Manufacturing Technology, chemical samples Names of ALL contributing authors: Po Jin, Qi Gao, Quanzhao Wang, and Wenbo Li.

\section{Declarations Funding}

This work was supported by the National Natural Science Foundation of China (No.51775100) and the Doctoral Start-up Fund of Liaoning Province (2019-BS-123).

\section{Conflicts of interest/Competing interests}

The authors have declared that no conflict of interest exists.

\section{Availability of data and material}

The data used to support the findings of this study are available from the corresponding author upon request.

\section{Authors' contributions}

The finite element simulation experiment of micromilling of $\mathrm{SiCp} / \mathrm{Al}$ composites was established. The milling process of $\mathrm{SiCp} / \mathrm{Al}$ composites with high volume fraction and large grain size was studied. The distribution of stress and strain of $\mathrm{SiC}$ reinforced particles and the material removal mechanism were analyzed. The influence degree of each influencing factor on surface roughness.

\section{Rreferences}

[1] Jishnu J. Bhattacharyya, R. Mitra. Effect of hot rolling temperature and thermal cycling on creep and damage behavior of powder metallurgy processed $\mathrm{Al}-\mathrm{SiC}$ particulate composite[J]. Materials Science \& Engineering A, 2012, 557(NOV.15):92-105.

[2] K. CChan, C. FCheung, M. VRamesh, W. BLeeSTo. A theoretical and experimental investigation of surface generation in diamond turning of an A16061/SiCp metal matrix composite[J]. International Journal of Mechanical Sciences, 2001, 43(9):2047-2068.

[3] S. Durante, G. Rutelli, F. Rabezzana. Aluminum-based MMC machining with diamond-coated cutting tools[J]. Surface \& Coatings Technology, 1997, 94(none):632640.

[4] Min Song. Effects of volume fraction of $\mathrm{SiC}$ particles on mechanical properties of $\mathrm{SiC} / \mathrm{Al}$ composites[J]. Transactions of Nonferrous Metals Society of China, 2009, 19(6):1400-1404.

[5] Cui Yan, Wang Lifeng, Ren Jianyue. Multi-functional $\mathrm{SiC} / \mathrm{Al}$ Composites for Aerospace Applications[J]. Chinese Journal of Aeronautics, 2008, 21(6):578-584 
[6] Tao Wang, Lijing Xie, Xibin Wang. Simulation study on defect formation mechanism of the machined surface in milling of high volume fraction $\mathrm{SiCp} / \mathrm{Al}$ composite[J]. The International Journal of Advanced Manufacturing Technology, 2015, 79(5-8):1185-1194.

[7] Xiangyu Teng, Dehong Huo, Wanqun Chen, Eugene Wong, Lu Zheng, Islam Shyha. Finite element modelling on cutting mechanism of nano $\mathrm{Mg} / \mathrm{SiC}$ metal matrix composites considering cutting edge radius[J]. Journal of Manufacturing Processes, 2018, 32(APR.):116-126.

[8] Zhichao Niu, Kai Cheng. An experimental investigation on surface generation in ultraprecision machining of particle reinforced metal matrix composites. 2019, 105(8):4499-4507.

[9] A. Pramanik, A.K. Basak, Yu Dong, Shankar Subramaniam, Guy Littlefair. Milling of Nanoparticles Reinforced Al-Based Metal Matrix Composites[J]. Journal of Composites Science, 2018, 2(1):13.

[10] Junwei Liu, Kai Cheng, Hui Ding, Shijin Chen. An analytical model for force prediction in micromilling silicon carbide particle-reinforced aluminum matrix composites[J]. Proceedings of the Institution of Mechanical Engineers Part B Journal of Engineering Manufacture, 2020, 234(10):095440542092341.

[11] U.A. Dabade, M.R. Jadhav. Experimental Study of Surface Integrity of $\mathrm{Al} / \mathrm{SiC}$ Particulate Metal-matrix Composites in Hot Machining[J]. Procedia CIRP, 2016, 41:914-919.

[12] Yingfei Ge, Jiuhua Xu, Yucan Fu. Experimental Study on High-Speed Milling of $\mathrm{SiCP} / \mathrm{Al}$ Composites[J]. Advanced Materials Research, 2011, 291-294:725-731.

[13] Junwei Liu, Kai Cheng, Hui Ding, Shijin Chen, Liang Zhao. An investigation of the influence of phases' removal ways on surface quality in micro milling SiCp/Al composites[J]. Procedia CIRP, 2018,71:59-64

[14] Beibei Wang, Lijing Xie, Xiaolei Chen, Xibin Wang. The milling simulation and experimental research on high volume fraction of $\mathrm{SiCp} / \mathrm{Al}[\mathrm{J}]$. The International Journal of Advanced Manufacturing Technology, 2016, 82(5-8):809-816.

[15] Tao Wang, Lijing Xie, Xibin Wang, Zhiwei Ding. PCD tool performance in high-speed milling of high volume fraction $\mathrm{SiCp} / \mathrm{Al}$ composites[J]. The International Journal of Advanced Manufacturing Technology, 2015, 78:1445-1453.

[16] Yanming Quan, Bangyan Ye. The effect of machining on the surface properties of $\mathrm{SiC} / \mathrm{Al}$ composites[J]. Journal of Materials Processing Tech, 2003, 138(13):464-467.

[17] R. Bian, N. He, L. Li, Z. B. Zhan, Q. Wu, Z. Y. Shi. Precision milling of high volume fraction $\mathrm{SiCp} / \mathrm{Al}$ composites with monocrystalline diamond end mill[J]. International Journal of Advanced Manufacturing Technology, 2013, 71(1-4):411-419.
[18] M. Bhuvanesh Kumar, R. Parameshwaran, K. Deepandurai, Senthil S M. Influence of Milling Parameters on Surface Roughness of Al-SiC-B4C Composites[J]. Transactions of the Indian Institute of Metals, 2020, 73(5).

[19] Xiangyu Teng, Wanqun Chen, Dehong Huo, Islam Shyha, Chao Lin. Comparison of cutting mechanism when machining micro and nano-particles reinforced $\mathrm{SiC} / \mathrm{Al}$ metal matrix composites[J]. Composite Structures, 2018, 203(NOV.):636-647.

[20] M.V. Ramesh, K.C.Chan, W.B. Lee, C.F. Cheung. Finite-element analysis of diamond turning of aluminium matrix composites[J]. Composites Science \& Technology, 2001, 61(10):1449-1456.

[21] Saeed Zare Chavoshi, Saurav Goel, Paul Morantz. Current trends and future of sequential micro-machining processes on a single machine tool[J]. Materials and Design, 2017, 127(aug.):37-53.

[22] Xiaoli Liu, Chunyi Su, Fan Yang. FNN ApproximationBased Active Dynamic Surface Control for Suppressing Chatter in Micro-Milling With Piezo-Actuators[J]. IEEE Transactions on Systems Man \& Cybernetics Systems, 2016:1-14.

[23] A. Pramanik, L.C. Zhang, J.A. Arsecularatne. An FEM investigation into the behavior of metal matrix composites: Tool-particle interaction during orthogonal cutting[J]. International Journal of Machine Tools \& Manufacture, 2007, 47(10):1497-1506.

[24] Li Zhou, S.T. Huang, D. Wang, X.L. Yu. Finite element and experimental studies of the cutting process of $\mathrm{SiCp} / \mathrm{Al}$ composites with PCD tools[J]. International Journal of Advanced Manufacturing Technology, 2011, 52(5-8):619-626.

[25] Y. Zhu, H.A. Kishawy. Influence of alumina particles on the mechanics of machining metal matrix composites[J]. International Journal of Machine Tools and Manufacture, 2005, 45(4-5):389-398.

[26] Y. Kan, Z.G. Liu, S.H. Zhang, L.W. Zhang, M. Cheng, H.W. Song. Microstructure-Based Numerical Simulation of the Tensile Behavior of SiCp/Al Composites[J]. Journal of Materials Engineering \& Performance, 2014, 23(3):1069-1076.

[27] G. Tursuna, U. Weber, E. Soppa, S. Schmauder. The influence of transition phases on the damage behaviour of an $\mathrm{Al} / 10 \mathrm{vol} . \% \mathrm{SiC}$ composite[J]. Computational Materials Science, 2006, 37(1-2):119-133. 


\section{Figures}

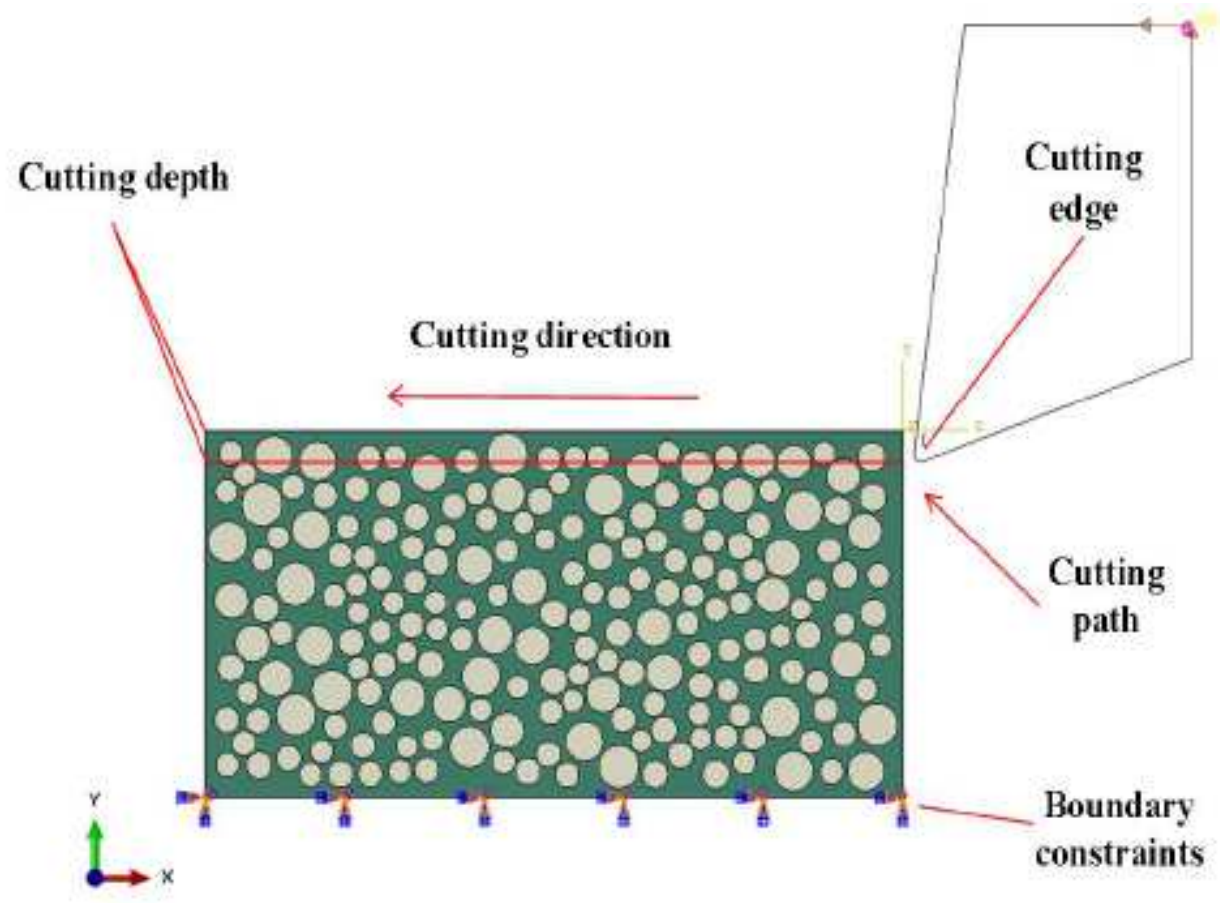

\section{Figure 1}

Schematic diagram of a milling model

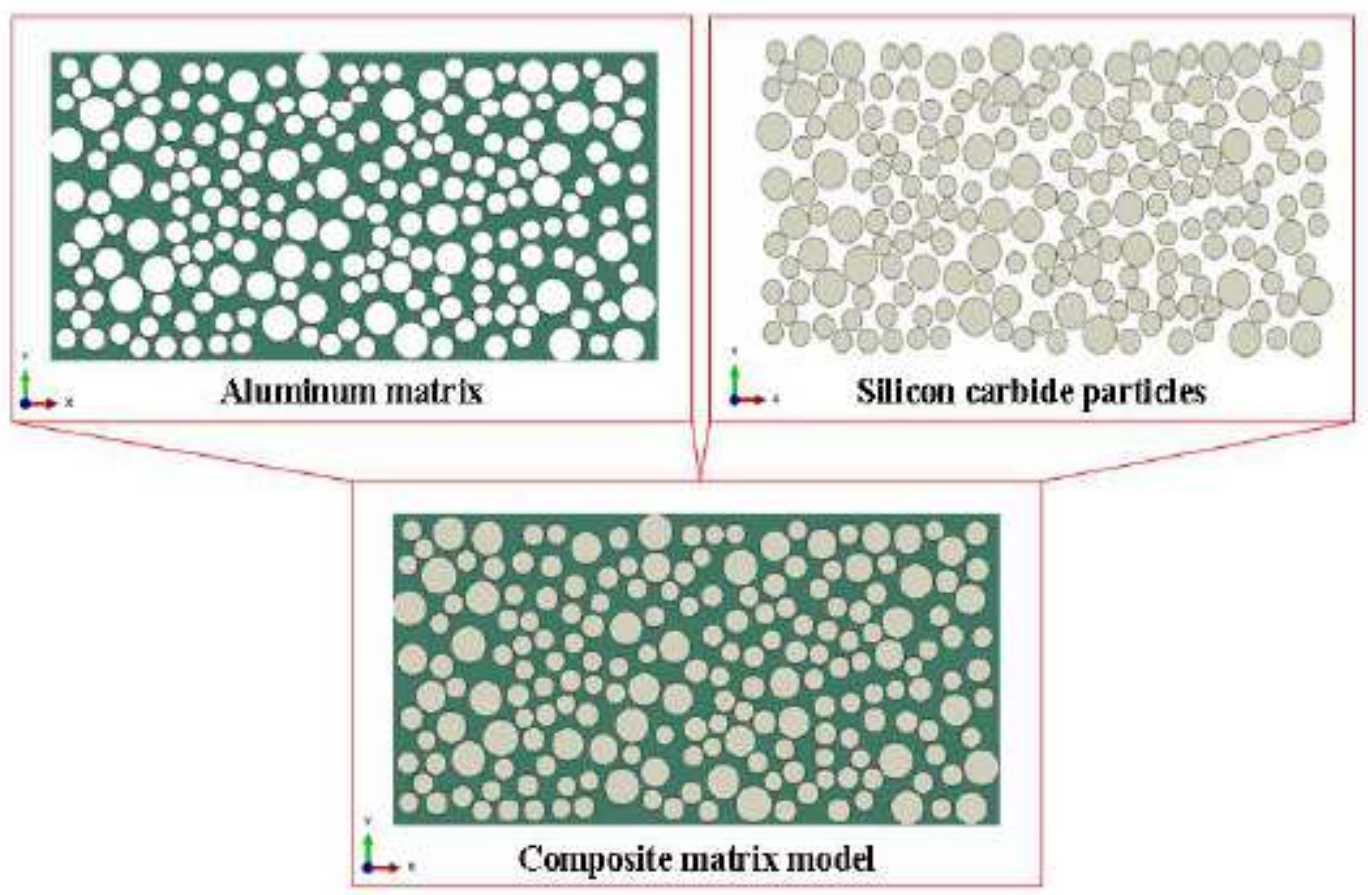

Figure 2

Two-dimensional finite element model of composite materials 
Tool feed direction

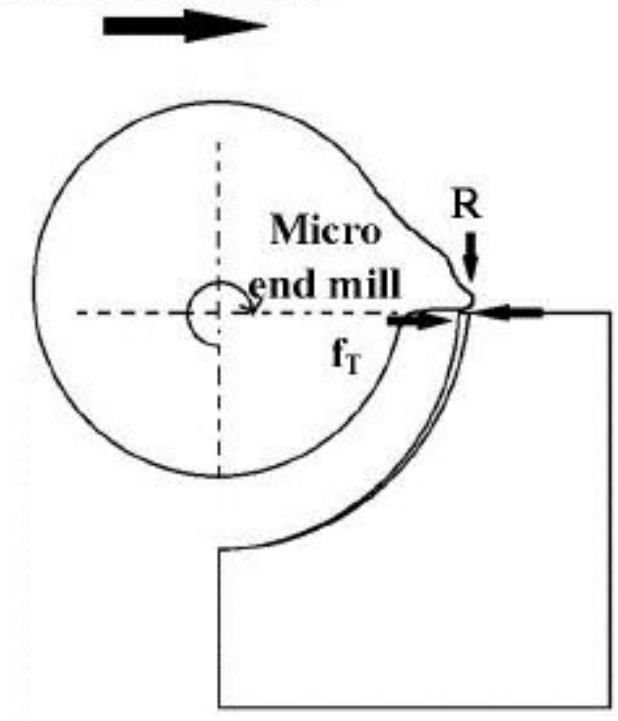

Top view of milling

Tool feed direction

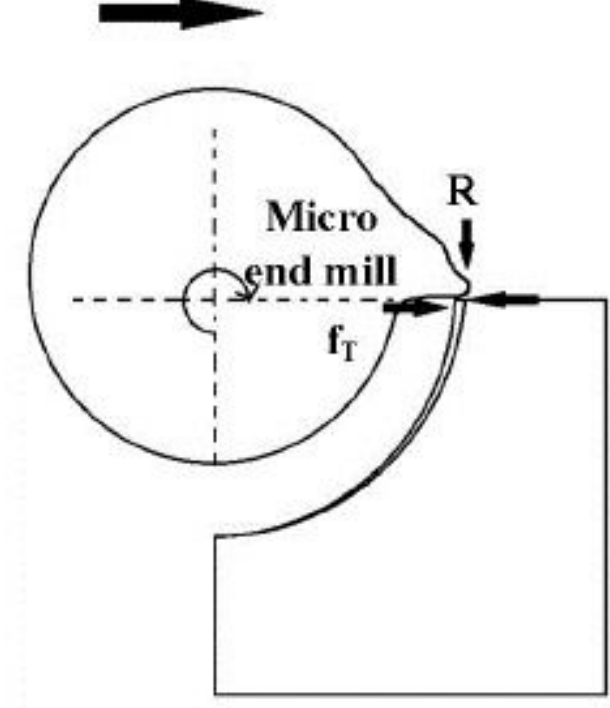

Top view of milling

(a)

(a)

\section{Figure 3}

Schematic Diagram of milling process (a) Overview diagram of milling; (b) Diagram of the relationship between milling and the orthogonal cutting model 

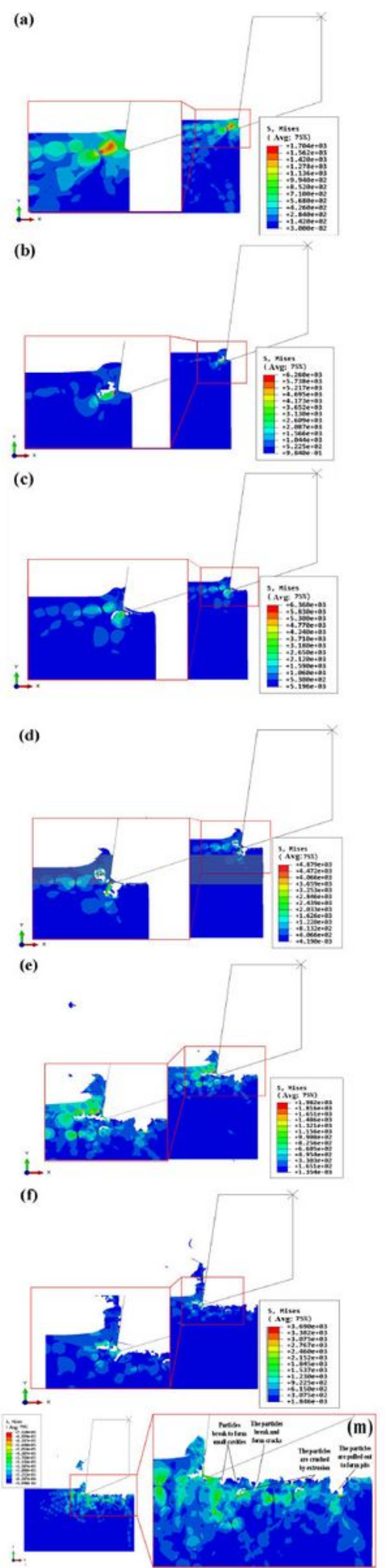

Figure 4

Removal mode and surface morphology of particles in simulation (a)-(I) C V =37.68 m/min, p a $=40 \mu \mathrm{m}$ particle removal mode; $(\mathrm{m}) \mathrm{C} \mathrm{V}=37.68 \mathrm{~m} / \mathrm{min}, \mathrm{p} \mathrm{a}=40 \mu \mathrm{m}$ surface morphology 

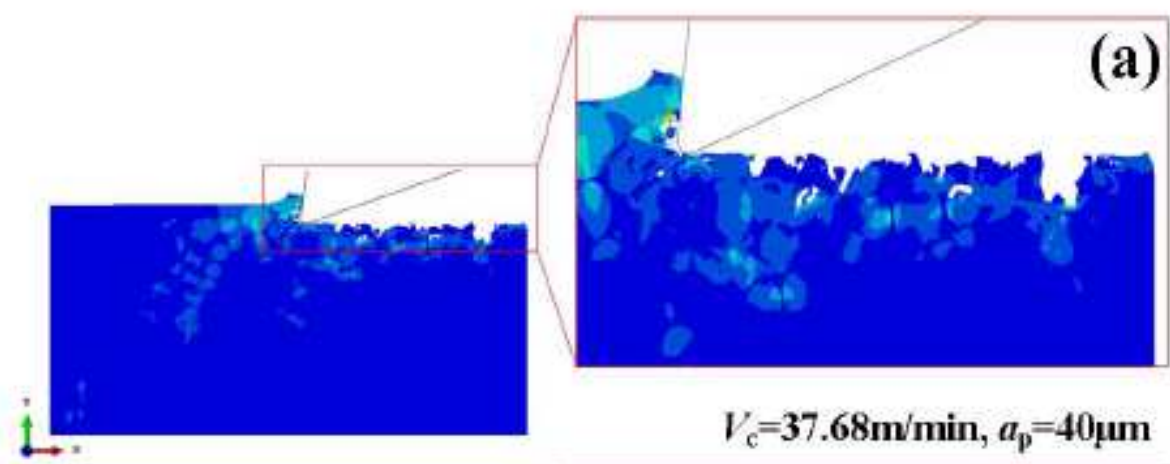

$V_{\mathrm{c}}=37.68 \mathrm{~m} / \mathrm{min}, a_{\mathrm{p}}=40 \mu \mathrm{m}$

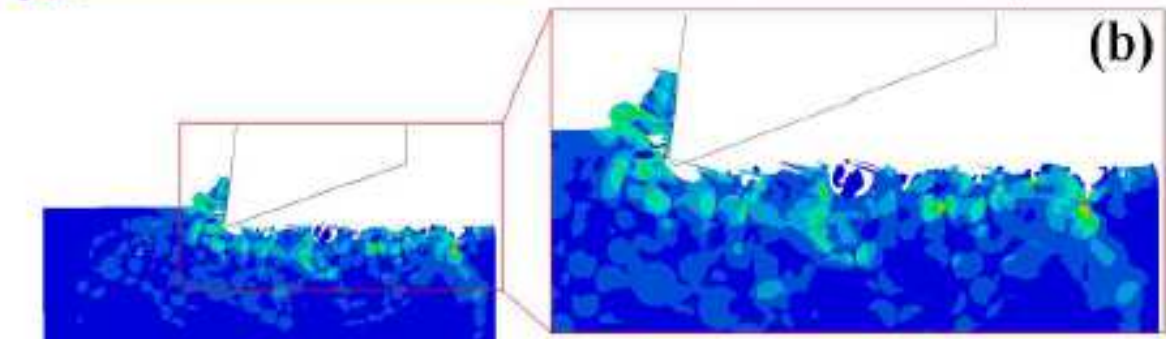

$V_{\mathrm{c}}=43.96 \mathrm{~m} / \mathrm{min}, a_{\mathrm{p}}=40 \mu \mathrm{m}$

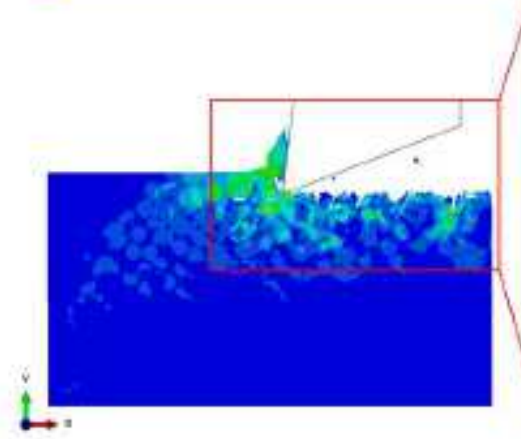

(c)

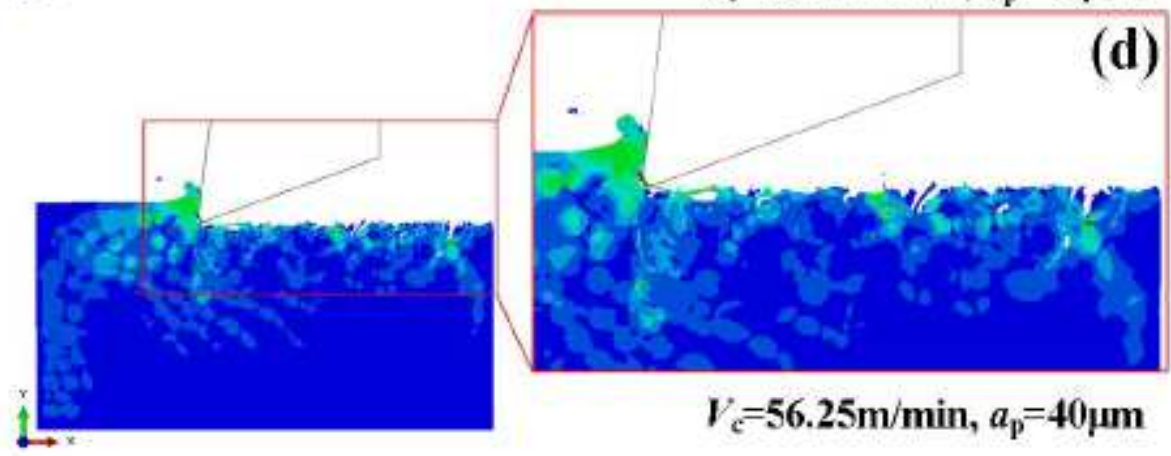

Figure 5

Morphology of SiCp/2024Al composite micromachined surface 


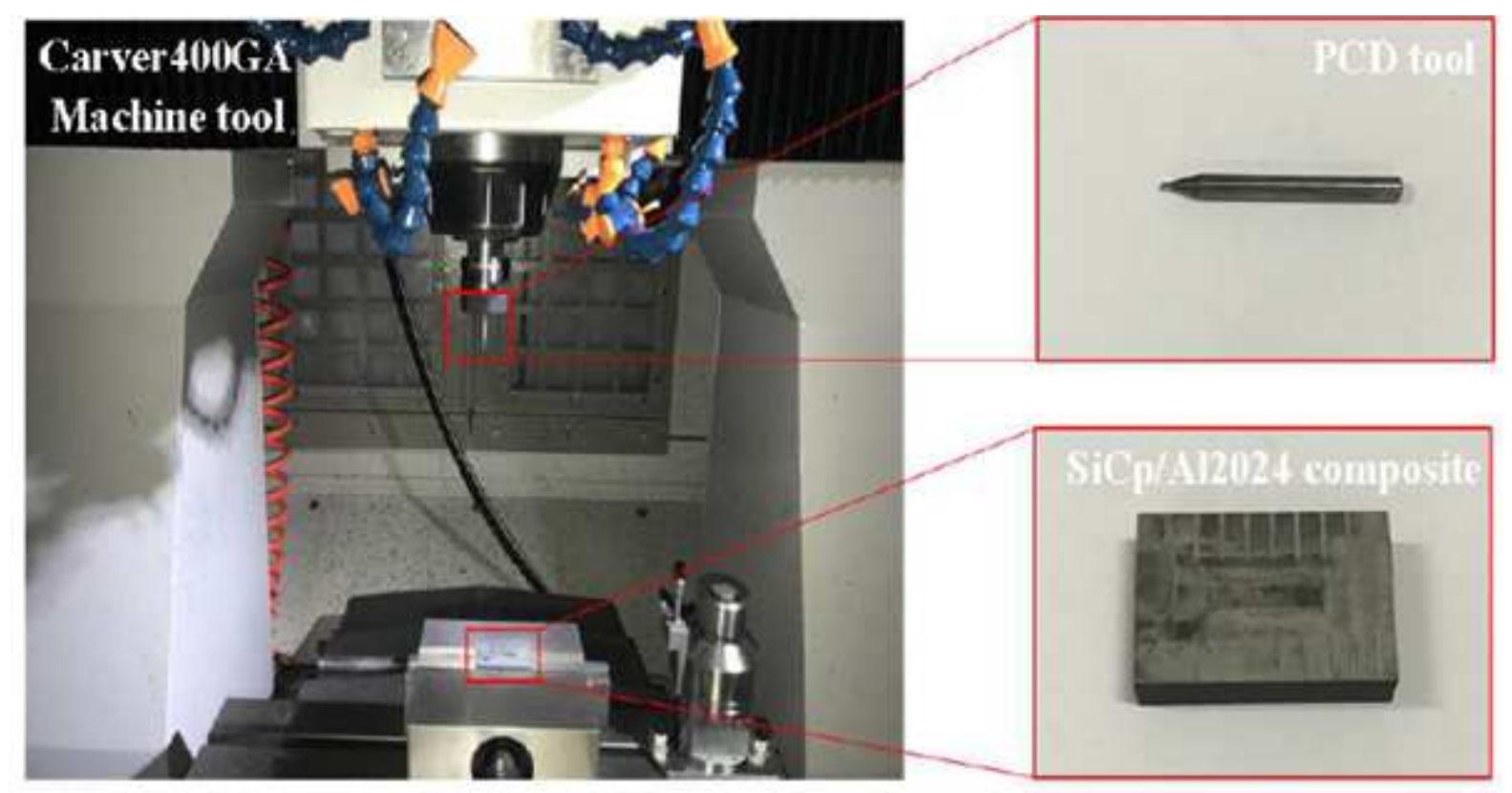

\section{Figure 6}

\section{Experimental site}
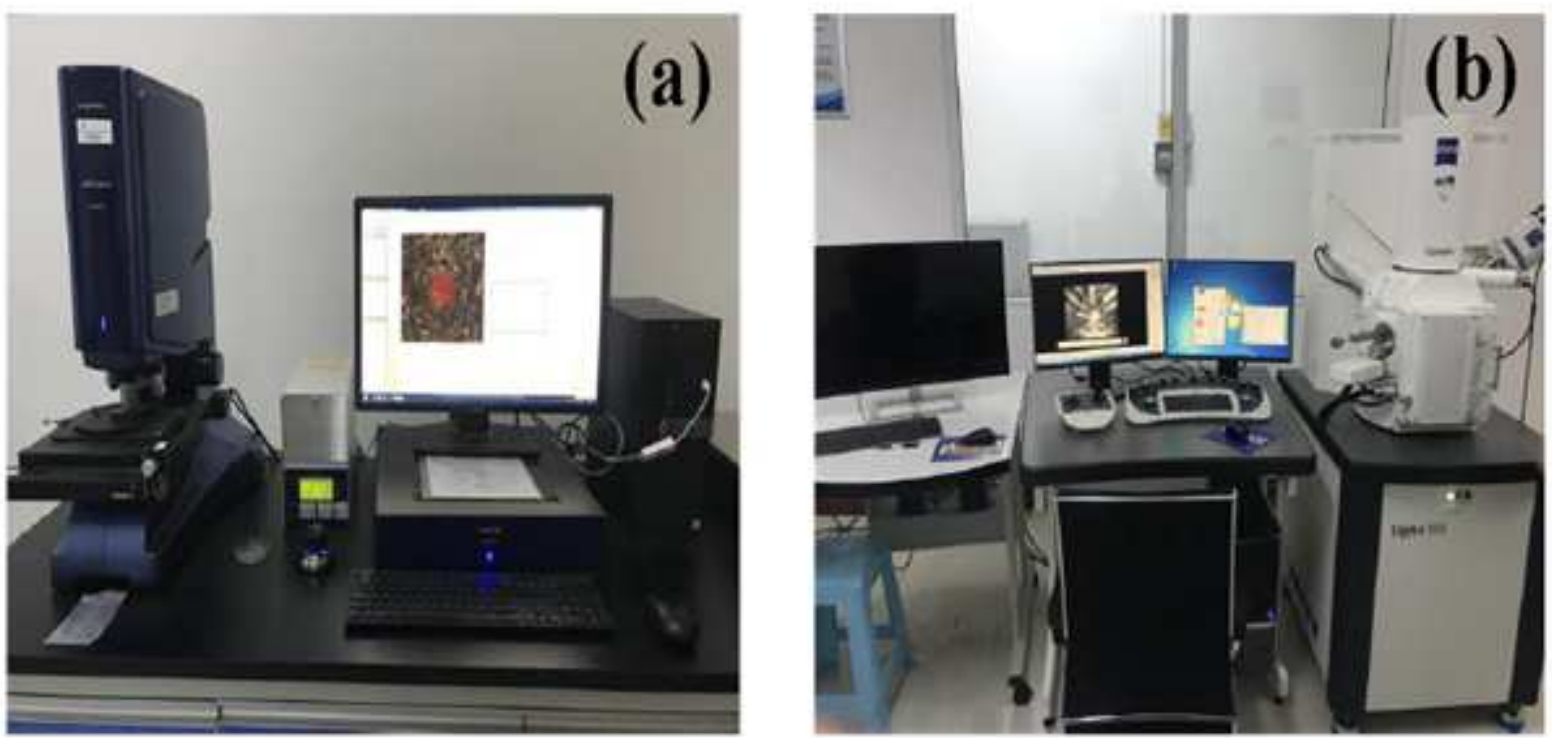

Figure 7

Experimental measurement equipment (a) True color confocal microscope; (b) Zeiss SIGMA 500 field emission scanning electron microscope 


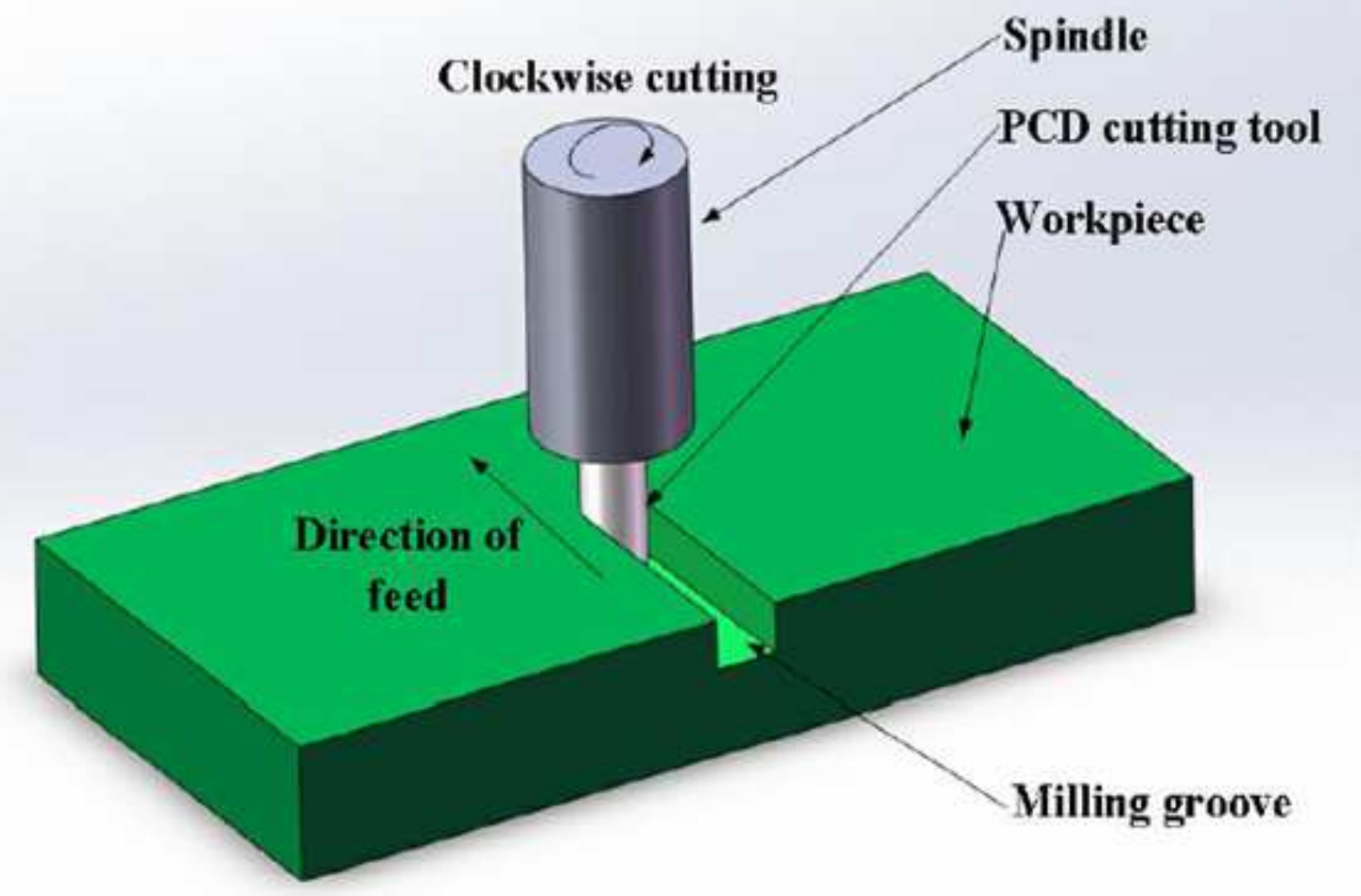

Figure 8

Schematic diagram of milling 


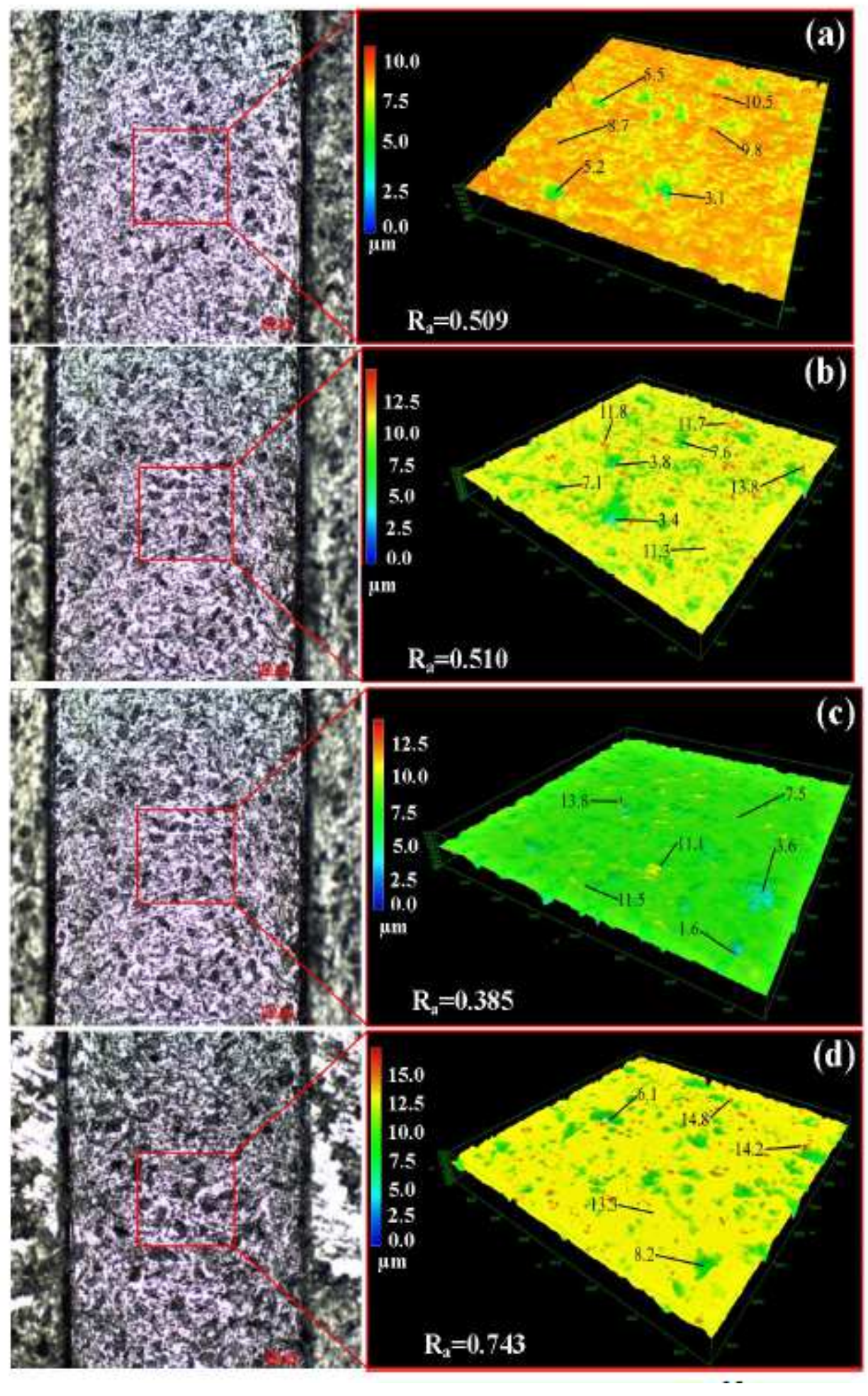

Figure 9

Three-dimensional feature map of surface morphology; (a) $\mathrm{N}=14000 \mathrm{r} / \mathrm{min}, \mathrm{f} \mathrm{V}=0.012 \mathrm{~m} / \mathrm{min}, \mathrm{p}$ a $=50$ $\mu \mathrm{m}$; (b) $\mathrm{N}=14000 \mathrm{r} / \mathrm{min}, \mathrm{f} \mathrm{V}=0.01 \mathrm{~m} / \mathrm{min}, \mathrm{p} a=50 \mu \mathrm{m}$; (c) $\mathrm{N}=16000 \mathrm{r} / \mathrm{min}, \mathrm{f} \mathrm{V}=0.006 \mathrm{~m} / \mathrm{min}, \mathrm{p}$ a $=40 \mu \mathrm{m}$; (d) $\mathrm{N}=18000 \mathrm{r} / \mathrm{min}, \mathrm{f} V=0.012 \mathrm{~m} / \mathrm{min}, \mathrm{p} a=20 \mu \mathrm{m}$ 

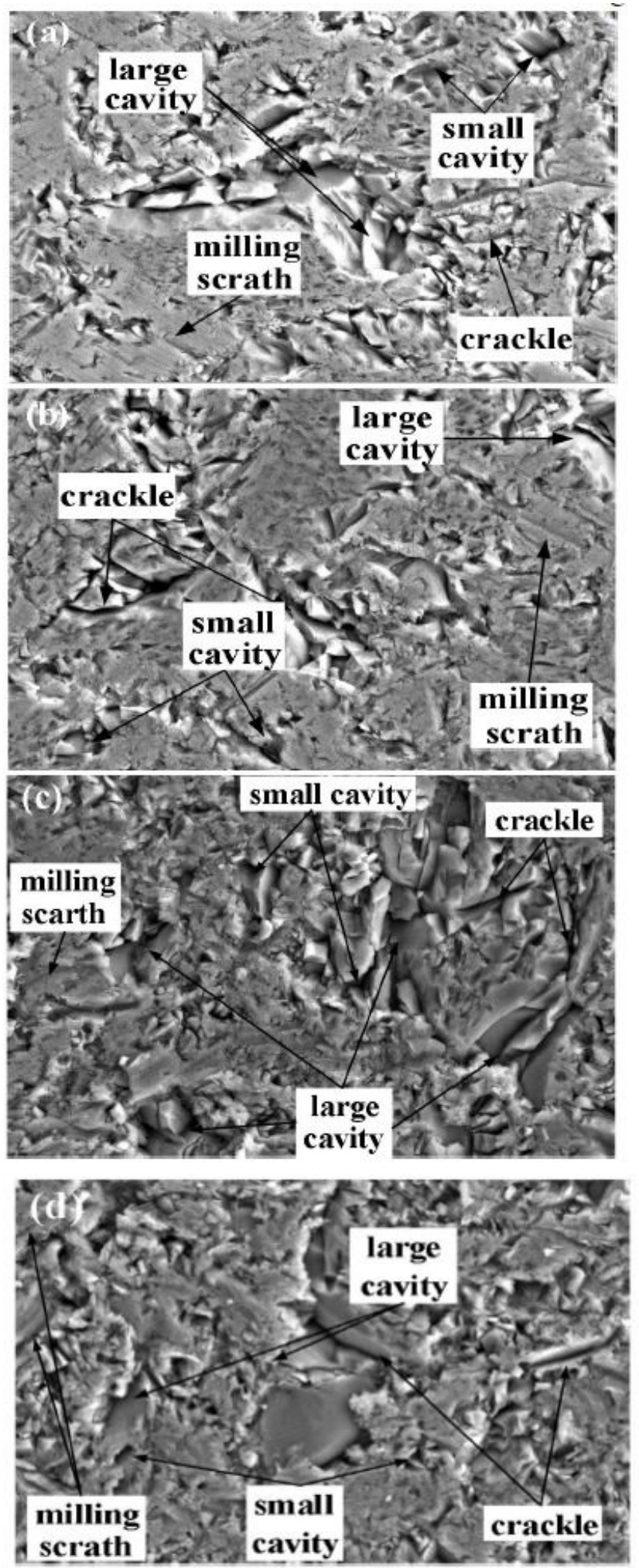

Figure 10

Material surface defect detection with the same milling depth and different feed per tooth; (a) $z f=0.5 \mu \mathrm{m}$, p a $=40 \mu \mathrm{m}$; (b) z $f=0.571 \mu \mathrm{m}, \mathrm{p} a=40 \mu \mathrm{m}$; (c) z $\mathrm{f}=0.625 \mu \mathrm{m}, \mathrm{p} a=40 \mu \mathrm{m} ;$ (d) $z \mathrm{f}=0.667 \mu \mathrm{m}, \mathrm{p} a=40 \mu \mathrm{m}$ 


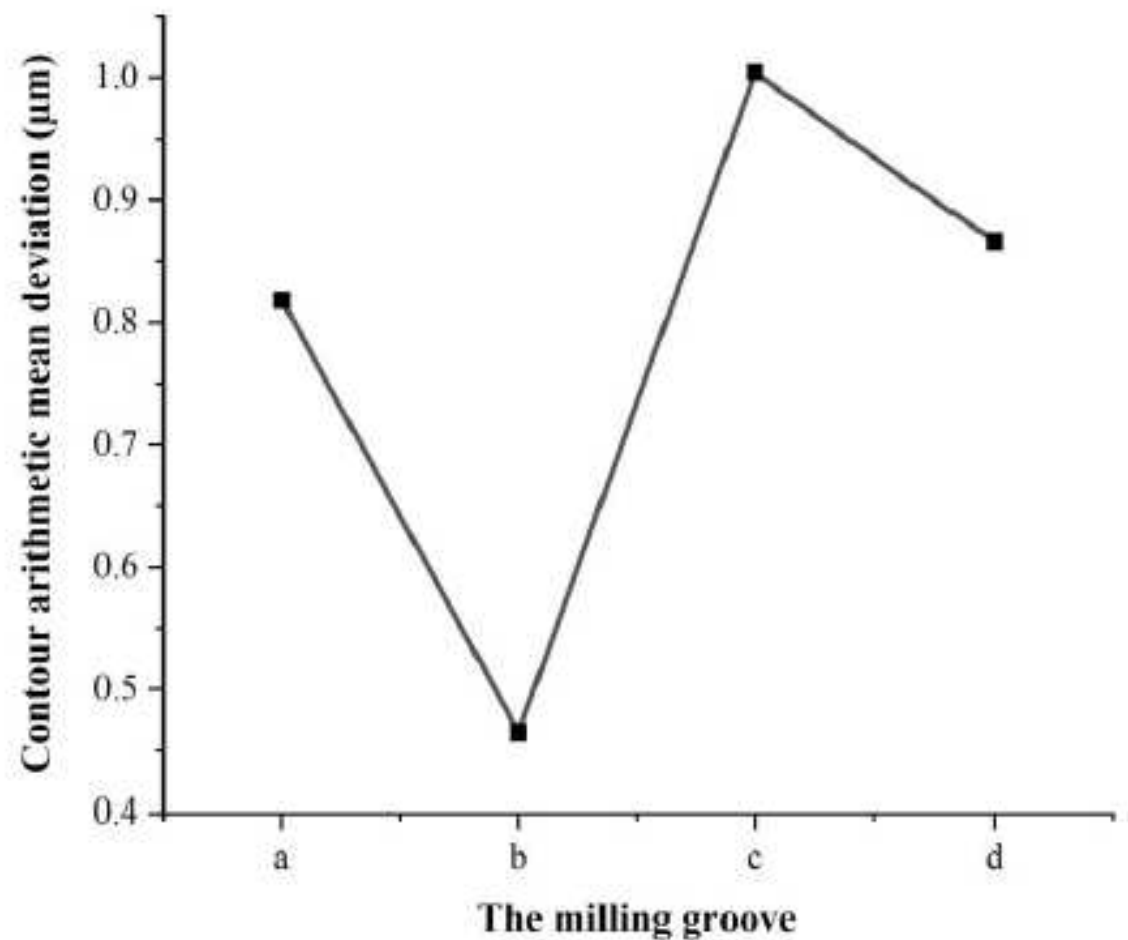

Figure 11

Surface roughness value corresponding to (a), (b), (c) and (d) 

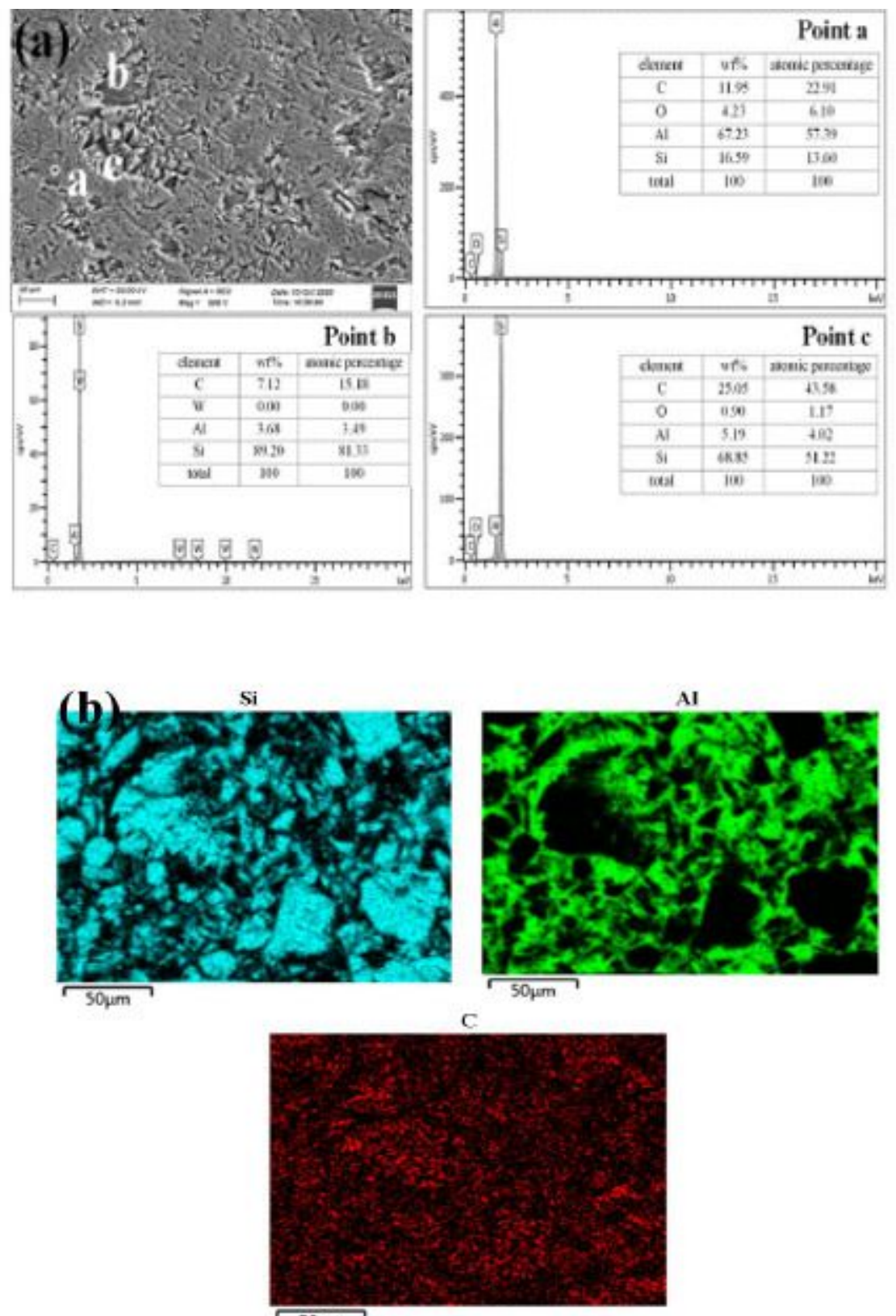

$\longdiv { 5 0 \mu \mathrm { m } }$

Figure 12

Composite material surface material detection diagram (a) Surface material point detection; (b) Surface detection surface scanning 


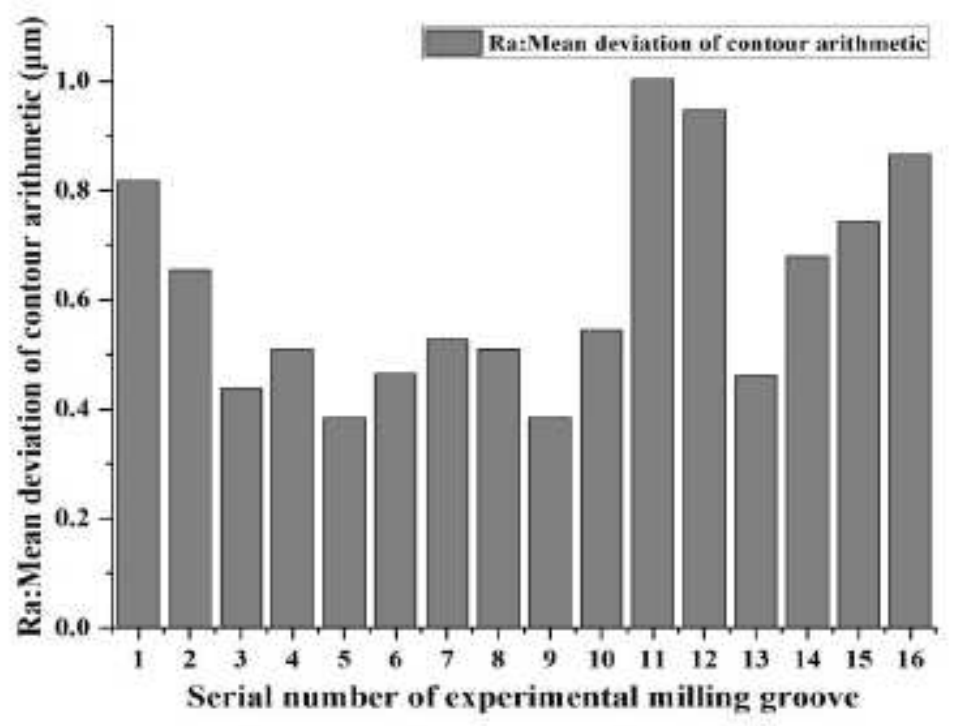

\section{Figure 13}

Measurement results of surface roughness of milling groove

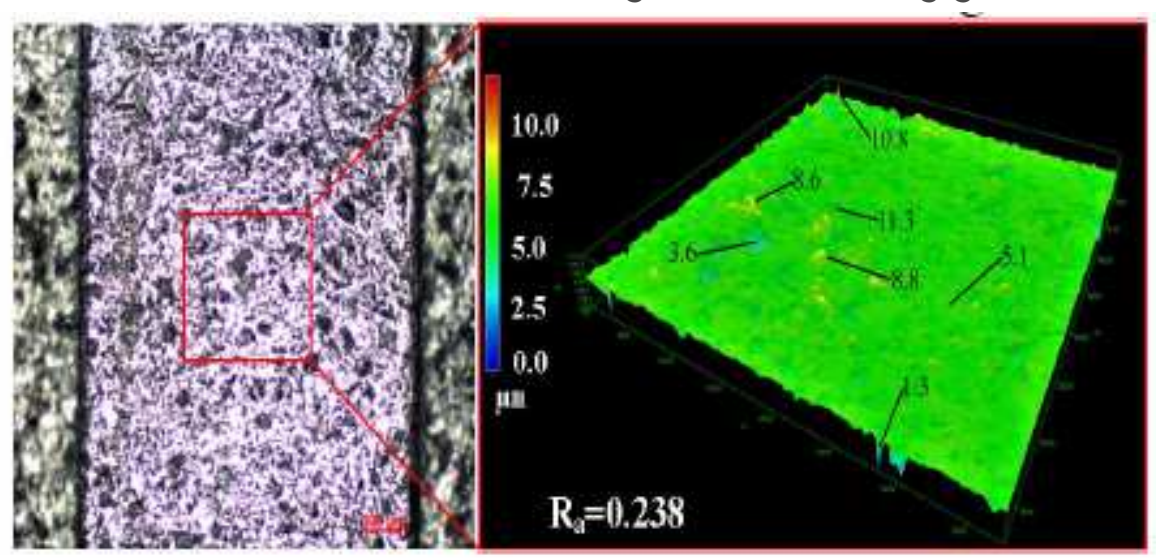

Figure 14

Surface 3D morphology characteristics of $N=14000 \mathrm{r} / \mathrm{min}, \mathrm{f} \mathrm{V}=0.006 \mathrm{~m} / \mathrm{min}$ and $\mathrm{p} \mathrm{a}=50 \mu \mathrm{m}$ 